\title{
Inefficient neural system stabilization: a theory of spontaneous resolutions and recurrent relapses in psychosis
}

\author{
Lena Palaniyappan, MD, PhD
}

\begin{abstract}
A striking feature of psychosis is its heterogeneity. Presentations of psychosis vary from transient symptoms with no functional consequence in the general population to a tenacious illness at the other extreme, with a wide range of variable trajectories in between. Even among patients with schizophrenia, who are diagnosed on the basis of persistent deterioration, marked variation is seen in response to treatment, frequency of relapses and degree of eventual recovery. Existing theoretical accounts of psychosis focus almost exclusively on how symptoms are initially formed, with much less emphasis on explaining their variable course. In this review, I present an account that links several existing notions of the biology of psychosis with the variant clinical trajectories. My aim is to incorporate perspectives of systems neuroscience in a staging framework to explain the individual variations in illness course that follow the onset of psychosis.
\end{abstract}

\section{Introduction}

A striking feature of psychosis is the heterogeneity of its presentation. Psychosis-like experiences occur commonly in the general population, often without notable functional consequences. In general health care settings, psychotic symptoms that significantly affect one's daily function occur in various disorders (e.g., delirium), often with full resolution. In psychiatric clinics, the course of psychosis varies from being a single, time-limited episode on one end of the spectrum to a tenacious illness at the other extreme, with a wide range of variable trajectories. Even among patients with schizophrenia, who are diagnosed on the basis of persistent deterioration, marked variation is present in response to treatment, frequency of relapses and degree of eventual recovery. Despite this, existing theoretical accounts of psychosis focus almost exclusively on how symptoms are initially formed, with much less emphasis on explaining their variable course. Thus, to date the focus of understanding the neurobiology of psychosis is largely at the symptom-formation level, rather than on the illness course in individuals. As a result, we continue to lack a physiologic framework to explain the wide range of variable outcomes that unravel to the point at which a patient experiences an initial episode of psychosis. In this article I attempt to construct an account that could link several existing notions of the biology of psychosis with the variant clinical trajectories. My aim is to put forward a thesis that could be invoked during a clinical dialogue with a concerned carer who is wondering why their loved one is presenting so differently from another patient attending the same treatment program.

First, I briefly review the concept of symptom resolution in psychosis and the evidence linking psychosis in general, and schizophrenia in particular, to cellular and systems-level brain connectivity. (The term "resolution" has been used to describe the reduction of symptoms to a level that is appreciable to the patient and care providers. The concept of durability of such resolution [i.e., remission] and its utility [i.e., recovery] are not the subjects of this review.) I will invoke existing ideas about the role of brain development, degeneration and plasticity to show how the concept of brain-network-level homeostasis can account for the varied course of psychosis. I also argue that the resolution of psychotic symptoms requires inherent homeostatic processes that, when aberrant, inhibit a fuller recovery. Finally, I highlight the aspects of psychotic illnesses that are not fully addressed by this framework and suggest future studies that are required to test the implications of the notions proposed here. I use the term "neural system stabilization" throughout this paper for the sake of simplicity, but this refers to the homeostatic process affecting all cellular constituents (i.e., glial cells and vasculature) that enable information transfer involving the entire brain.

Correspondence to: L. Palaniyappan, Robarts Research Institute, 100 Perth Drive, London, ON N6A 5K8; Ipalaniy@uwo.ca

Submitted Mar. 13, 2018; Revised Feb. 7, 2019; Accepted Mar. 5, 2019; Published online June 27, 2017

DOI: $10.1503 / j p n .180038$ 


\section{Onset and resolution of psychosis}

Psychotic disorders are clinically defined by and diagnosed based on the presence of delusions and hallucinations alongside deficits in processing speed, attention, verbal fluency, emotional expression, logicality and coherence of thought. These symptoms have a high probability of co-occurrence in some patients and demonstrate a variable degree of resolution after first presentation.

Several features of the natural course of psychosis call for explanation. ${ }^{1,2}$ Isolated psychotic experiences such as voicehearing and delusion-like ideas occur regularly among otherwise healthy individuals. ${ }^{3,4}$ Although these experiences are mostly transitory, ${ }^{5,6}$ the epidemiological risk factors for such experiences overlap substantially with those of psychotic disorders with conventionally poorer outcomes, such as schizophrenia. ${ }^{3,4}$ People with psychosis-like experiences or the more tightly defined constructs of at-risk states or schizotypal disorder are at a higher risk of developing full-blown psychosis, but the majority of those who experience such transient psychotic states do not develop a psychotic episode; ${ }^{7,8}$ the risk of conversion peaks at 2 years and drops with longer follow-up periods. ${ }^{9}$

The onset of psychosis is often insidious or subacute in schizophrenia $\left(53 \%{ }^{10}\right.$ to $\left.70 \%{ }^{11}\right)$, but it can be florid and acute in many other psychotic disorders. ${ }^{12}$ The insidious prodromal stage in schizophrenia frequently presents with anxiety related to often numerous random coincidental associations and primitive perceptual aberrations, ${ }^{13-15}$ but at the peak of a fully evolved episode, psychosis is characterized by a limited number of stereotyped and fully formed delusions and hallucinations that tend to repeat. ${ }^{16}$ As psychosis evolves, patients often appear to add further elaborations to this limited set of delusions and hallucinations, rather than forming completely unrelated ideas (see Table 1 for first-person accounts ${ }^{17-19}$ ).

A substantial number of patients with first-episode psychosis have only 1 episode. ${ }^{20-22}$ Globally, the incidence rates of such acute and transient psychotic disorders are consistently higher than the incidence of schizophrenia. ${ }^{23,24}$ Psychosis can resolve without treatment in some of these patients. ${ }^{21,25}$ Longitudinal studies conducted before the advent of neuroleptics remind us that these numbers are large enough to not be dismissed. ${ }^{26}$ When appropriate treatment is started, a large number of first-episode patients show an early symptomatic response; ${ }^{27,28}$ such an early reduction in the severity of delusions and hallucinations predicts a favourable later outcome. ${ }^{29-31}$ Resolution of delusions does not usually involve "extinction" or "unlearning" the associations underlying psychotic beliefs; instead, it involves a gradual ability to detach from the pressure of the beliefs and perceptual abnormalities. ${ }^{15,32}$ While positive symptoms become less prominent with the course of illness, cognitive deficits and negative symptoms remain stable. ${ }^{33-35}$

Relapses can occur even in adequately medicated patients (primary relapse), ${ }^{36,37}$ but the rates of relapse are distinctly higher in those who discontinue treatment in the early stages of illness (interventional relapse). ${ }^{38,39}$ When relapses occur during the course of illness, irrespective of the duration of the intervening period of recovery, the same predictable set of symptoms tends to recur with each episode. ${ }^{40,41}$ Furthermore, unlike the first episode of psychosis, which is preceded by a long duration of prodromal symptoms and a gradual buildup of unusual experiences, relapses often occur without a similar insidious prodrome. ${ }^{36}$ With each relapse, treatment resistance becomes more likely, especially when the relapse occurs after discontinuation of antipsychotic therapy. ${ }^{36,39}$ Notwithstanding this phenomenon, a small proportion of patients achieve good function despite a high number of early relapses. ${ }^{42-44}$

\section{Progressive structural changes of the brain in psychosis}

One of the most consistent neuroimaging observations in patients with psychosis is a reduction in the amount of grey matter volume and thickness measured using MRI. ${ }^{45,46}$ These grey matter deficits are present even in the early stages of a patient's life $\mathrm{e}^{47,48}$ and are shared to some extent by their healthy siblings. ${ }^{49-51}$ Once the early psychotic symptoms come to the surface, these grey matter deficits appear to intensify, ${ }^{52,53}$ especially in the first few years, ${ }^{54}$ before slowing down. ${ }^{55}$ Some reports indicate a continuous but low level of ongoing grey matter reduction, even in much later stages. ${ }^{56,57}$ The extent of the grey matter deficits relates to both the severity of illness ${ }^{58-60}$ and the degree of exposure to agents that are associated with relapses and functional disability. ${ }^{55,61,62}$ In addition, rather controversially, longitudinal grey matter reduction is more pronounced in those who have higher cumulative

Table 1: First-person accounts of delusional activity

\begin{tabular}{|c|c|}
\hline Author & Excerpt \\
\hline Chadwick $^{17}$ & $\begin{array}{l}\text { As my delusional system expanded and elaborated, it was as if I was not "thinking the delusion," the delusion was "thinking me!" I was } \\
\text { totally enslaved by the belief system. Almost anything at all happening around me seemed at least "relevant" and became, as Piaget } \\
\text { would say, "assimilated" to it. Another way of putting things was that confirmation bias was massively amplified, everything confirmed and } \\
\text { fitted the delusion, nothing discredited it. Indeed, the very capacity to notice and think of refutatory data and ideas was completely gone. }\end{array}$ \\
\hline Chapman ${ }^{18}$ & $\begin{array}{l}\text { I often misinterpreted real-life occurrences such as the behaviours of others as somehow related to those conspiring against me. When } \\
\text { people passed by (police cruisers, door-to-door salespeople), I thought they must be there to spy on me. When I half-heard a } \\
\text { conversation in the distance or the honking of a car, I would think it held special significance for me. I would randomly open a dictionary } \\
\text { and find a word ("die," "liar," "evil") and interpret how the word had special meaning for me. }\end{array}$ \\
\hline Powell $^{19}$ & $\begin{array}{l}\text { After the first hospitalization, it was almost predictable that every } 4 \text { years my mother's behaviour appeared to change in the fall ... } \\
\text { Although my mother tried desperately to recuperate from each psychotic episode and each arrest, she became increasingly reclusive and } \\
\text { paranoid. Each episode was precipitated by an erotomanic delusion or delusions of persecution in the workplace that followed shortly } \\
\text { after the psychiatrist decided to taper her antipsychotic medications. }\end{array}$ \\
\hline
\end{tabular}


exposure to antipsychotic medications (with some differences between typical and atypical drugs). ${ }^{52,63,64}$ Nevertheless, at several brain regions, these changes appear to be reversible. Certain types of nondrug therapies appear to reverse or slow the structural changes in patients. ${ }^{65-68}$

Not every patient with psychosis shows progressive structural deficits, but in those who do show such grey matter changes, there seems to be a predilection for certain brain regions, including the superior temporal, ${ }^{53,60,69-75}$ lateral frontal, $^{71,72,75,76}$ insular ${ }^{52,60,70,73,77}$ and anterior cingulate ${ }^{70,71}$ cortex on a more consistent basis, followed by the thalamus, ${ }^{75}$ precuneus ${ }^{76}$ and inferior parietal ${ }^{75}$ and hippocampal ${ }^{74}$ regions somewhat less consistently. Interestingly, in the large-scale organization of correlated brain activity and structural connectivity, these regions constitute the so-called "hubs"78 or "rich clubs"79 in the human brain. Hubs and rich-club regions typically form the most connected nodes in the overall network architecture of the human brain and consequently show higher levels of overall activity..$^{80,81}$ The connectional architecture and activity load experienced by these regions make them particularly vulnerable to structural damage in diffuse brain disorders such as schizophrenia. . $^{81,82}$

The widespread structural changes in psychotic disorders are often discussed in the context of either extended aberration in neurodevelopment or a limited form of neurodegeneration. While earlier theorists used the term degeneration to refer to the longitudinal changes in psychosis, it is now increasingly clear that neither a progressive neuronal loss nor a relentless clinical deterioration characteristic of true neurodegeneration occurs in psychotic disorders, leading to a preference for the term neuroprogression to denote postonset brain changes. ${ }^{83}$ An overwhelming number of observations now exist that are interpreted as signs suggestive of aberrant neurodevelopment in schizophrenia. ${ }^{84-88}$ An equally strong line of argument exists for a limited form of neuroprogression. ${ }^{89-92}$ Several attempts to bridge the 2 notions have been made in recent times. ${ }^{93-97}$ Most of the proposed compromises hinge on the notion that a healthy adult brain continues to develop and change in structure over time; ${ }^{98,99}$ a developmental aberration would continue to affect brain structure in adult life, thus explaining the neuroprogression in schizophrenia. ${ }^{100}$

\section{Psychosis as a disorder of connectivity}

The notion that psychosis is related to aberrant connectivity in the brain originated in the 19th century. ${ }^{101-104}$ The initial concept of disconnection was based on the manifest disconnection in thoughts, actions and behaviour seen in patients with psychosis. Various elegant theories later resurrected, refined and pinned this idea to the brain level, with the aid of postmortem and neuroimaging studies in the last 20 years. ${ }^{105-109}$ The 3 key pillars of the dysconnectivity hypothesis are (1) the reduction in neuropil, the tissue zone that normally houses a large number of neuronal synapses, observed in postmortem brains of patients with schizophrenia; ${ }^{107,110,111}$ (2) abnormal increases and decreases in the correlation of activity among various brain regions (functional con- nectivity) measured using positron emission tomography, MRI, electroencephalography and magnetoencephalography studies; ${ }^{108,112}$ and (3) abnormal increases and decreases in the indices of white matter integrity (structural connectivity) measured using diffusion tensor imaging. ${ }^{113,114}$ These observations arise from different measurement tools used at different spatial and temporal scales and activity levels, but they are notably reconcilable at a whole brain (systems) level ${ }^{115,116}$ and speak to a reduction in the ability to transfer information within affected brains.

Although there are notable spatial variations in the patterns of resting-state functional connectivity in relation to psychosis, some patterns are now emerging consistently with improvised data-processing approaches. ${ }^{117,118}$ Functional hyperconnectivity, especially affecting the prefrontal cortex, is more pronounced during early stages of schizophrenia, ${ }^{119,120}$ relates to positive rather than the negative symptoms of the illness $^{119,121,122}$ and normalizes to some extent with antipsychotic treatment. ${ }^{123,119}$ Such functional hyperconnectivity also results from external agents that typically induce psychotic symptoms. ${ }^{124,125}$ Ketamine, an agent that produces nearly all of the core symptoms of schizophrenia in healthy humans, produces robust hyperconnectivity involving the prefrontal cortex. ${ }^{125-130}$ In particular, this resting-state hyperconnectivity involves a set of brain regions that constitute the default-mode network. ${ }^{122,131,132}$ These regions characteristically show an elevated level of activity at rest and appear relatively deactivated when a person is engaged in task performance. ${ }^{133}$ In contrast to the prefrontal/default mode network hyperconnectivity in the early stages, a wider hypoconnected resting state is often noted in later stages of schizophrenia. ${ }^{12,120,126}$

Certain emerging observations provide clues as to the neural process that may underlie the hyperconnectivity between 2 brain regions seen in resting-state functional MRI. First, hyperconnectivity is often seen during the initial response to neuronal injury. ${ }^{134,135}$ Second, training and new learning in healthy brains results in an early increase in functional connectivity in relevant brain regions, along with hypoconnectivity. ${ }^{136,137}$ Even in the absence of a learning exercise, coordinated electrical/magnetic neural stimulation (plasticity-inducing paradigms) results in functional hyperconnectivity, indicating a Hebbian increase in neural communication at a synaptic level. ${ }^{138}$

\section{The concept of neural system stabilization}

The human brain can be regarded as a connected system that tolerates any faults by restoring itself. This concept has its roots in 3 broad theoretical notions: (1) Bernard and Cannon's notion of "homeostasis" in biological systems; ${ }^{139,140}$ (2) the notion of self-organization in dynamic physical systems; ${ }^{141-143}$ and (3) the concept of fault tolerance employed in cybernetics, based on Dijkstra's original network theory. ${ }^{144-146}$ In this section, I consider how these processes can scale up from synaptic to the macro-connectome level.

Homeostasis is a ubiquitous regulatory process that serves to maintain the function of a system at a set activity level, providing stability. ${ }^{147}$ The human brain is constantly 
bombarded by events and objects in the environment that evoke neuronal activity; in addition, constant spontaneous activity is also a feature of neuronal existence. ${ }^{148,149}$ Given the thousands of synapses that each neuron has with many other neurons, accidental coincidence of stochastic or stimulus-driven firing between 2 (or more) neurons is highly likely in this milieu. ${ }^{150}$ Hebbian rules of plasticity dictate that such coincidental spikes of activity will result in strengthening of the synaptic connectivity between the 2 neurons. ${ }^{151,152}$ But such an associative, input-specific learning process is often destabilizing to the neuronal ensemble, because it sets up the constituent neurons for either runaway hyperactivity or global silencing. ${ }^{147,153,154}$ If left unchecked, such a system can end in a hyperconnected or hypoconnected mode, ${ }^{155}$ neither of which is optimal for new learning or information transfer. ${ }^{156,157}$ The maintenance of both sparse functional connectivity and a steady baseline activity with low energy consumption are important for the status quo of the human brain. ${ }^{158}$

Several modes of homeostatic compensation operate to reduce the resulting instability; ${ }^{159,160}$ some of these involve functional rebalancing by stabilizing the firing rate of a neuron (intrinsic plasticity), tuning the inhibitory inputs (inhibitory plasticity) or down-weighting synapses (scaling). ${ }^{161}$ In addition, structural alterations, such as changes in synaptic size, synaptic number and the dendritic spine structure (structural plasticity) either co-occur or serve as a second-level homeostatic mechanism. ${ }^{160,162,163}$ Reduced connectivity at the synaptic level is compensated for by an increase in the size $\mathrm{e}^{164,165}$ and number of synapses, and reduced neuronal activity (e.g., via input deprivation) results in reduced synaptic elimination. ${ }^{166}$ These normal physiologic processes that regulate neuronal excitability or synaptic strength continuously degrade the absolute effect of synaptic coding that occurs with associative learning, but preserve the essential memory traces. ${ }^{153}$ Together, the homeostatic processes serve to maintain the overall excitatory and inhibitory balance in local neuronal ensembles that constitute the global brain connectome. ${ }^{167}$ This enables a connectome-wide system stabilization that facilitates optimal signal processing and learning. ${ }^{168}$ Such readiness is a prerequisite for continuous adaptation to one's environment. ${ }^{169}$ A similar self-restoring function has been described in various computational systems with distributed control, especially in the context of systemic fault tolerance that ensures the return of a perturbed system to its legitimate state in the service of global objectives. ${ }^{144,145}$

The notion of neural system stabilization in the global brain connectome refers to the scaled-up systemic effects of the homeostatic process operating at the synaptic level to maintain sparse connectivity and optimal activity, as summarized in Figure 1.

\section{Psychosis and inefficient neural system stabilization}

In the following section, I provide an account of how a disruption in neural system stabilization can result in the var- ied presentations of psychotic experiences. First, I propose that several factors can disrupt the stable pattern of timingdependent coincidence detection at a neural level.

The first factor is intrinsic hyperactivity: a neural tissue with anomalously high frequency of activity can result in an increased probability of associative plasticity. Depending on the location of this activity, at an experiential level, we can speculate that people may experience brief sensory or cognitive disruptions of a fleeting nature. Several studies of people who were hallucinating have reported an elevated level of neural activity involving sensory cortices. ${ }^{170,171}$

The second factor is disturbances in the normal constraints on associative plasticity. A cardinal feature of Hebbian plasticity is dependence on the temporal order of coincidental neuronal activation; ${ }^{172}$ under certain circumstances, this temporal window can be prolonged, increasing the probability of formation of coincidences. For example, dopamine and substances that induce an excess release of dopamine could potentiate this mechanism. ${ }^{173}$

The third factor is failure of habituation: repeated presentation of the same stimulus elicits progressively smaller neuronal response. ${ }^{174}$ Disruptions in this habituation could prolong the state of evoked neuronal activity, increasing the probability of coincidences. ${ }^{175}$ A large body of electrophysiological studies points toward a habituation deficit in psychosis. ${ }^{17-178}$ At an experiential level, we can speculate that people may report a lack of feeling of familiarity for events, again increasing ambiguity and uncertainty. ${ }^{175}$

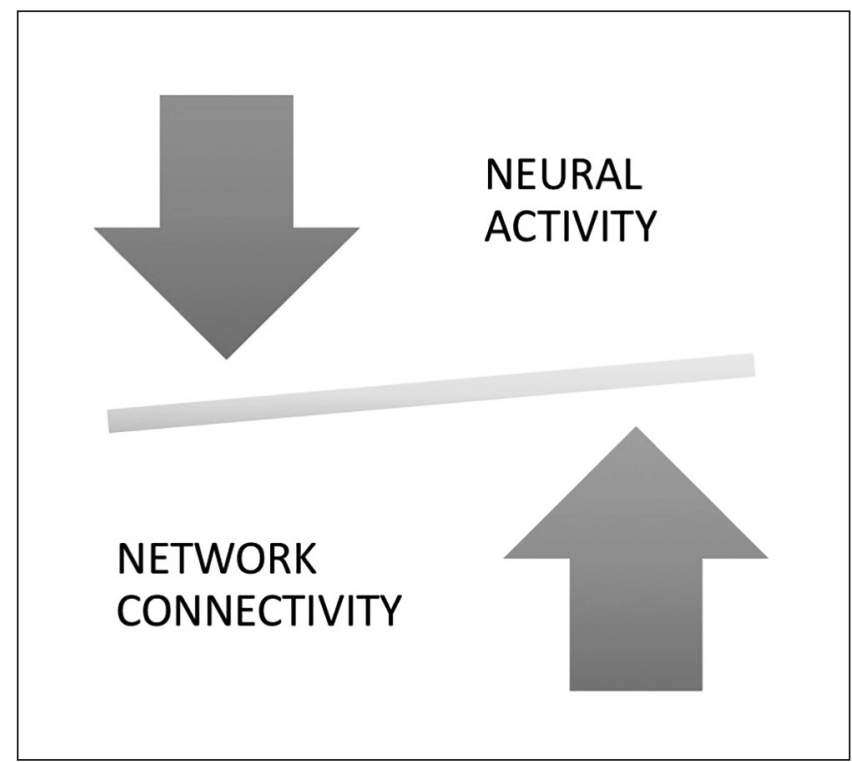

Fig. 1: Illustration to reflect the balance between physiologic outputs of a neural unit (i.e., neuronal firing "activity") and the social influence on the component unit ("connectivity"). If neuronal firing is excessive, the balance tilts, leading to engagement of homeostatic mechanisms that reduce the connectivity and restore the balance. Conversely, if synaptic strength/number (connectivity) is reduced, this triggers a compensatory increase in neuronal firing. This neural system stabilization helps to maintain topological homeostasis, likely characterized by a narrow range of "tuned states" of the brain connectome. 
Although these aberrations clearly have the potential to generate psychotic experiences (Fig. 2), in each case, in the presence of an intact homeostatic plasticity, the synaptic coding will be weakened and eliminated. Thus, these disruptions can produce periodic psychosis-like experiences and prodromal features on their own but are insufficient to produce a psychotic episode. If agents that induce the above neural states are repeated frequently or occur in massive doses, then a temporary overload of homeostatic mech- anisms can ensue, leading to a psychotic episode, although with a high probability of full resolution with or without treatment (Fig. 3). A likely example is the clinical presentation of drug-induced psychosis with full resolution. If this is the case, what is the necessary condition for the emergence of a schizophrenia-like illness?

I propose that in certain people, aberrant (nonstructural) homeostatic plasticity leads to a lack of resolution of coincidental associations. In such cases, synaptic strengthening

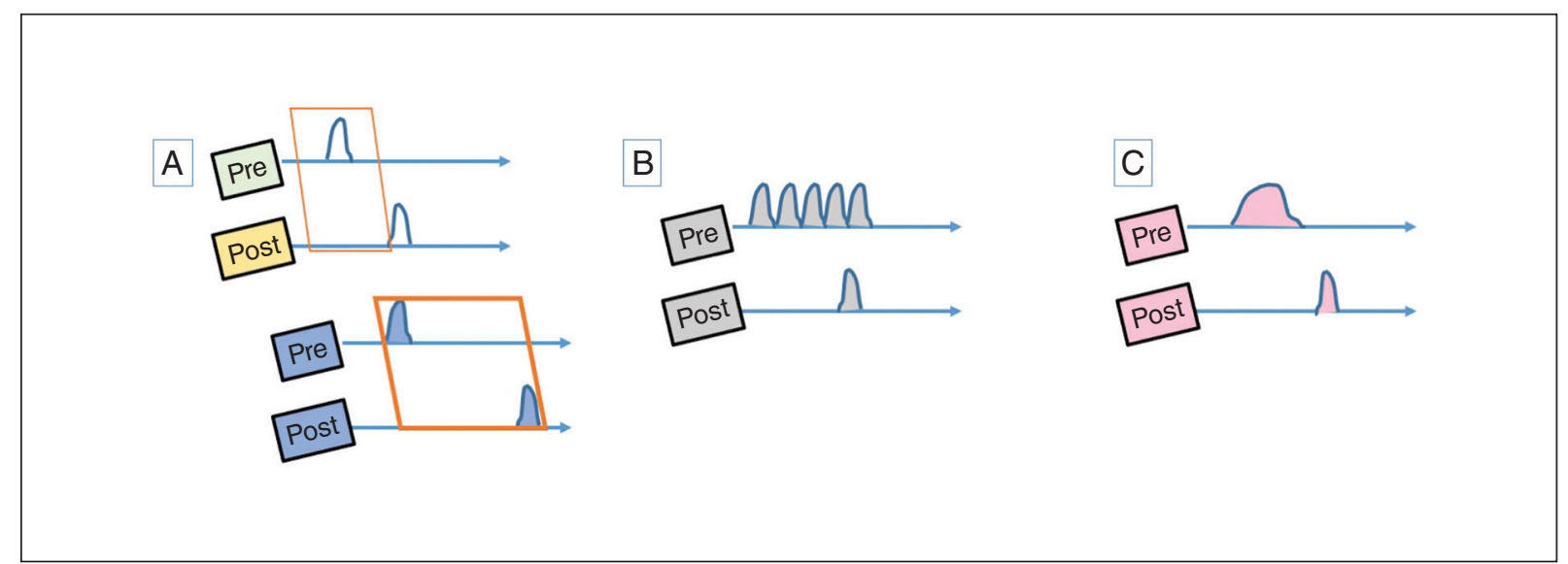

Fig. 2: Anomalous associations and psychotic experiences. (A) Learning associations between 2 time-variable signals require tight temporal coordination (Hebbian window), shown as a narrow interval between the activation of pre- and postsynaptic neurons in the first illustration. This window can be prolonged in hyperdopaminergic states, as shown in the lower panel. (B) Anomalous bursts of presynaptic activity can lead to inadvertent Hebbian associations. (C) Failure of habituation may lead to prolonged states of evoked activity, increasing the probability of Hebbian associations.

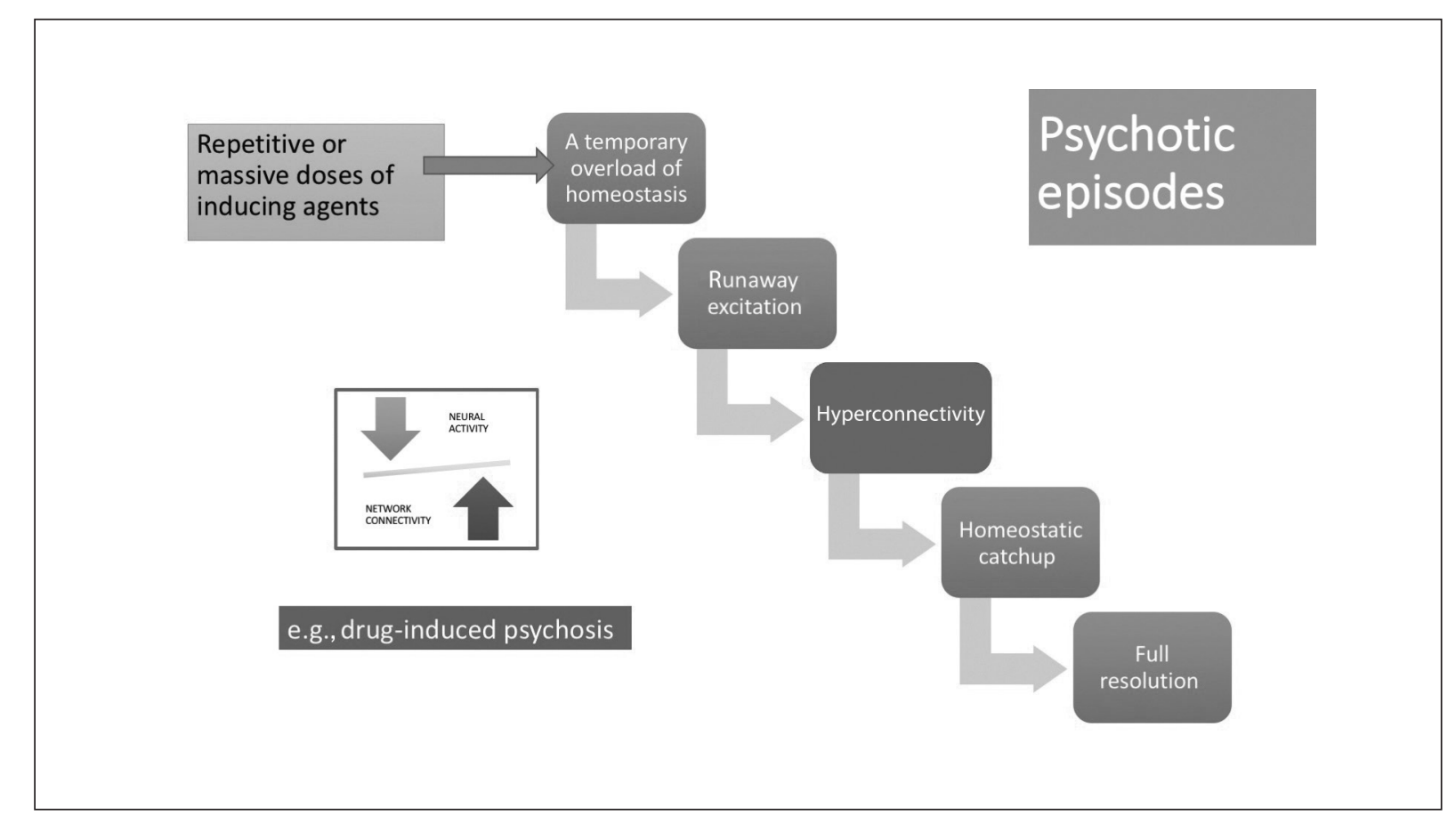

Fig. 3: Stabilization lag in a psychotic episode. Psychotic episodes can occur after repetitive or massive doses of inducing agents through mechanisms shown in Figure 2, leading to a temporary overload of neural system stabilization. Provided that the cellular/topological system stabilization apparatus (homeostatic) is intact, these episodes can resolve fully. 
accumulates (often insidiously) and the neuronal ensemble harbouring such coincidental associations eventually experiences a runaway excitation, forming a strong feed-forward loop that would quickly incorporate other correlations to the initial association (delusional elaboration characteristic of a psychotic episode), resulting in a state of indiscriminate hyperconnectivity in the proximate network space of the affected ensemble. In such circumstances, a recurrent, stereotyped temporal pattern is set in motion that can persist for an abnormally long period of time ("burnt into memory"155). This hyperconnectivity enables instantaneous recruitment of neuronal modules that are not normally involved in the processing of a given stimulus or task ("spreading activation"), producing the apparent hyperactivity in distant sites that is often reported in patients with psychosis. Topologically, the connectome now appears to be "subtly randomized" as sparsity in the connectivity is lost (as described by Rubinov and colleagues ${ }^{179}$ ). In the absence of homeostatic resetting, synaptic strengths of the affected neuronal core become fully saturated, precluding the formation of new associations that are required for extinction. Thus, once fully formed in an individual with inherent defects in homeostatic plasticity, the extinction of delusions becomes highly unlikely. Furthermore, the lack of neural system stabilization also reduces the connectome's general readiness to process further inputs, thus reducing the speed of signal processing, expressed clinically as the negative symptom of psychomotor poverty. In addition, the suboptimal messagepassing that occurs in an overloaded connectome (Fig. 4) can result in temporal delays in communication among modular brain units. This in turn can affect the temporal segregation required to separate self-generated from external mental content, ${ }^{180-182}$ resulting in an aberrant sense of self. Thus, selfrelated disturbances and negative symptoms are more likely in those who have aberrations in neural system stabilization.

With the sustained and diffuse destabilization of the connectome that affects its sparse connectivity, the need for alternate homeostatic processes involving structural plasticity are triggered. ${ }^{162,183,184}$ Structural plasticity involves synaptic elimination and retraction of spines that aim to restore the sparse connectivity state that existed before the onset of psychosis. This process gradually eliminates excitatory dendritic synapses, with consequent neuropil reduction ${ }^{107,185}$ and progressive grey matter loss. Owing to the inherently higher activity levels and their propensity to be highly accessible to most of the aberrant neuronal ensembles, rich-club hubs of the human connectome (anterior cingulate cortex, insula, lateral prefrontal cortex, superior temporal gyrus and hippocampal regions) are most likely to be affected by this global retuning process. $78,81,82,186$ With time, this leads to "de-escalation" of hubs and restoration of sparse connectivity, albeit at the cost of increased segregation of functional modules and prolonged transit time in the network (Fig. 5).

This structural homeostatic compensation eventually succeeds in abolishing the recurrent spreading of the avalanche of activity originating in anomalous neuronal ensembles. This comes at the cost of somewhat lower efficiency of information transfer, which becomes apparent whenever the demands on the system increase. Patients at this stage of illness exhibit a lower level of psychotic symptoms, but they continue to express negative symptoms (reduced speed of information processing, avoidance of social demands). One of the unintended consequences of hub/rich-club damage is the emergence of peripheral hubs, often located in unimodal cortices. These peripheral hubs, although they now have a higher degree of functional connectivity than other brain regions, lack the richness of hierarchical structure possessed by conventional core hubs. As a result, the flexibility of resource allocation is reduced at a global level, resulting in a reduction of system-wide plasticity and producing inefficient information transfer, especially when demands are placed on the networks. In addition, reduced overall connectivity increases the propensity of higher neural activity (Fig. 1), creating fertile soil for further relapses. Psychosis-inducing triggers continue to produce further episodes at this stage, although with reduced homeostatic reserve - both intrinsic and structural even milder doses of inciting agents may now be sufficient to induce relapses. ${ }^{187,188}$ Furthermore, compensation through dendritic spine reduction reaches a critical point after repeated relapses with no further room for spine reduction, leading to a state of "homeostatic occlusion" (Fig. 6). In people who reach this stage, treating psychotic episodes becomes more difficult, taking longer and requiring higher doses, and some episodes will remain treatment-resistant.

Many other agents that may worsen the outcome of established illness can directly induce dendritic spine elimination. ${ }^{189}$ Drugs of abuse also alter the dynamics and microstructure of both dendrites and dendritic spines, ${ }^{190}$ chronic stress also promotes synaptic elimination. ${ }^{191}$ In addition, activity dependence of structural synaptic plasticity means that at least some of synaptic elimination could be secondary to lack of environmental stimulation. ${ }^{192}$ When the first psychotic episode occurs at a very early age, accompanying developmental processes synergistically hasten dendritic spine reduction, resulting in accelerated homeostatic occlusion and early emergence of treatment resistance.

Dopamine regulates the gain of $N$-methyl-D-aspartate (NMDA)-receptor-mediated Hebbian associative plasticity. ${ }^{193}$ Antipsychotics, by blocking D2 receptors, may act directly at the synaptic milieu to inhibit the associative learning process. They also facilitate the intrinsic functional homeostatic plasticity that counteracts the Hebbian potentiation, reducing the time taken for symptom resolution. ${ }^{194,195}$ In particular, typical neuroleptics result in the inhibition of long-term potentiation and spike-timing dependent plasticity. ${ }^{194}$ This effect rapidly reduces the runaway facilitation that occurs at the synaptic level during a psychotic episode, facilitating the resolution of the psychosis (early responders) and restoring the efficient sparse connectivity. ${ }^{196}$ Nevertheless, in patients with defective intrinsic homeostasis such rapid response may not occur; in addition, when response occurs eventually, discontinuation or dose reduction may carry a higher risk of relapse. Further, antipsychotics also increase oxidative stress, which may trigger or indirectly facilitate structural synaptic plasticity. ${ }^{197}$ With long-term use, certain antipsychotics (especially atypicals) may have a propensity to reduce synaptic elimination, halting or reducing the neuropil reduction that may occur in 


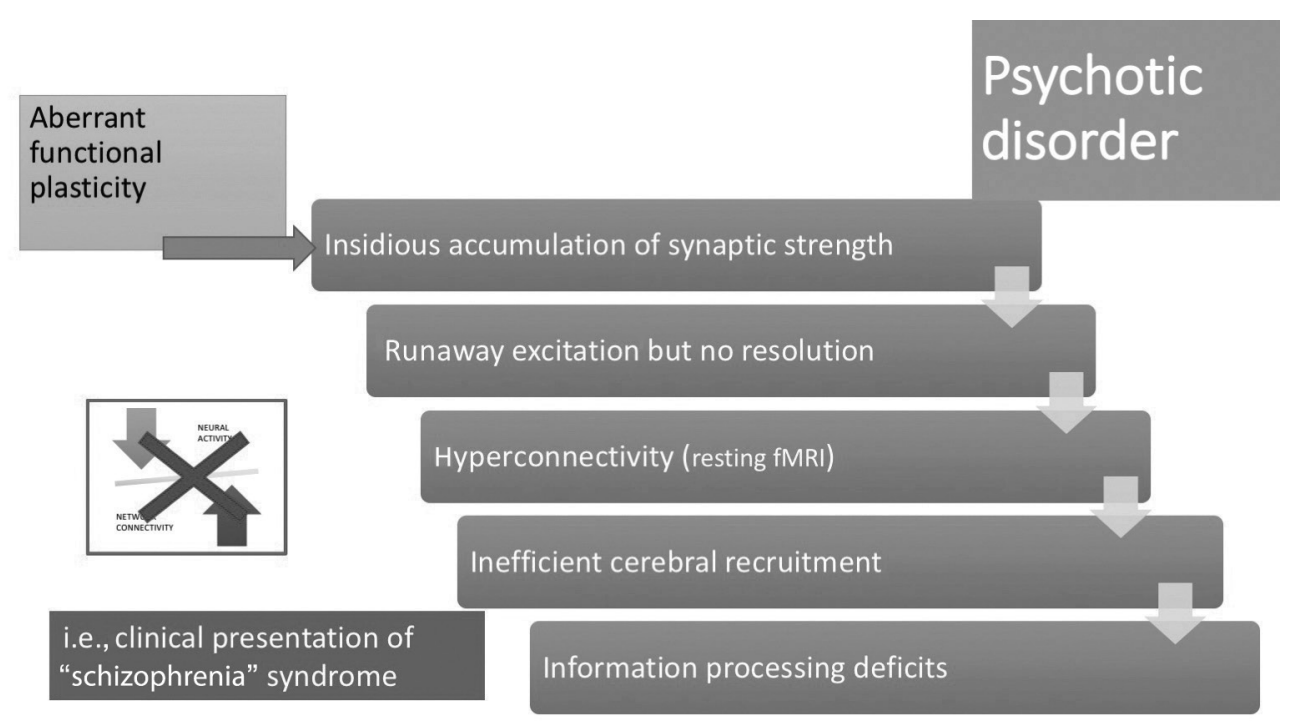

Fig. 4: Stabilization shift in psychotic disorders. In those who have a predilection for aberrant functional plasticity, synaptic gains from associations accumulate over time, leading to runaway excitation in the neural network. The occurrence of this event may be brought forward by exposure to inducing agents, as indicated in Figure 3 . In the absence of an intact neural system stabilization process, this results in a hyperconnected state for resting-state brain networks, with inefficient overrecruitment of task-processing regions. Subtle information-processing deficits that accompanied the predilection for aberrant functional plasticity now become more pronounced; the step change coincides with the first psychotic episode. The neural system stabilization mechanism now shifts from inefficient functional plasticity to a robust dependence on structural plasticity (i.e., spine reduction). $\mathrm{fMRI}=$ functional $\mathrm{MRI}$.

A

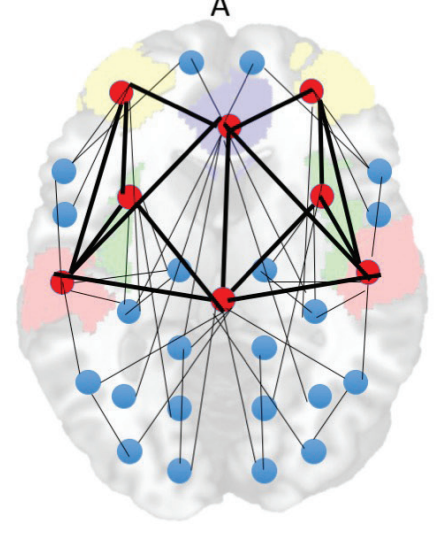

B

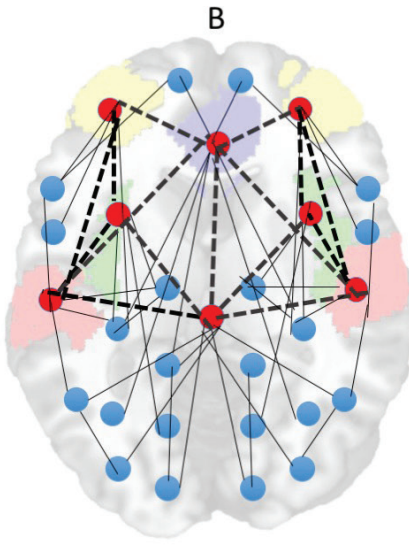

C

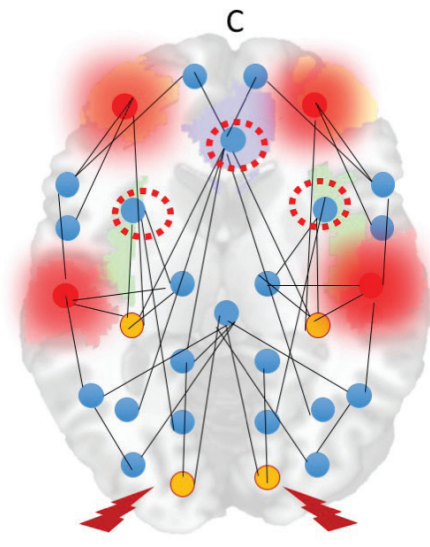

Fig. 5: Hub de-escalation in psychotic disorders. (A) Rich-club hubs of the human connectome (anterior cingulate cortex, insula, lateral prefrontal cortex, superior temporal gyrus and hippocampal regions) have inherently high activity levels and higher topological proximity to any given brain region. (B) As a result, the pathways to and from these nodes are most likely to be the sites of dendritic spine reduction occurring in response to anomalous hyperconnectivity. (C) With time, this leads to "deescalation" of hubs (red-dotted circles), increased demands on remaining hubs (overloading effect, shown with a red halo) and emergence of peripheral hubs (yellow nodes). While this helps with restoration of sparse connectivity, it comes at the cost of increased segregation of functional modules (nodes with a thunderbolt sign less well connected to other hubs) and prolonged transit time in the network. 
schizophrenia, ${ }^{198}$ and typical antipsychotics may alter synaptic proteins, facilitating dendritic spine regression and neuropil reduction. ${ }^{199}$ Critchlow and colleagues ${ }^{200}$ demonstrated a 59\% increase in primary dendritic spine density in rat hippocampal neurons upon clozapine administration, while haloperidol had an opposing effect (see also Bringas and colleagues ${ }^{201}$ ). This suggests that clozapine may have specific effects on dendritic spines that may help restore structural plasticity, even in later stages of treatment resistance.

Excessive anomalous associations due to abnormalities in timing-dependent plasticity may result in psychotic experiences; if agents inducing such abnormalities are repeated frequently or in occur massive doses, then homeostatic mechanisms may experience temporary overload. This leads to a psychotic episode that can resolve with or without treatment, if the process of system stabilization is intact. In individuals with aberrant functional plasticity, inefficient cerebral recruitment and processing deficits occur, resulting in the clinical syndrome of psychotic disorders such as schizophrenia. In this state, hub de-escalation and suboptimal retuning of the global connectome provide fertile ground for relapses. With successive relapse, a state of homeostatic occlusion occurs, leading to a treatment-resistant profile.

\section{Neural system stabilization, sex and developmental age}

Brain development is characterized by critical time windows in which the system stability of the brain is notably affected.
Such windows are characterized by an increase in structural homeostatic activity that helps to restore the stability. For example, adolescence is associated with crucial changes in the profile of NMDA receptors, which mediate functional synaptic plasticity (a subunit switch from NR2B to NR2A) $)^{202,203}$ and the dopamine receptor D2, which affects inhibitory plasticity. ${ }^{204}$ During this critical period, excitatory synapses are actively eliminated, ${ }^{204-206}$ increasing the inhibitory tone required for balanced brain activity. I posit that the emergence of psychosis is more common during late adolescence because excess demands are placed on structural plasticity at this time. Furthermore, homeostatic plasticity is the major mechanism of experience-dependent shaping of the developing brain. Any perturbation in this system-such as the one proposed here as a mechanism for psychosis-is bound to have a developmental effect that can present itself even before the onset of psychosis (e.g., disrupted asymmetry, ${ }^{207}$ folding defects $\left.{ }^{208}\right)$. In particular, invocation of structural homeostatic plasticity could be related to an increased vulnerability of oxidative stress, which plays a crucial role in synaptic elimination. ${ }^{209,210}$ This may explain why obstetric complications such as neonatal hypoxia and consequent developmental defects are more likely to be seen in patients who later develop schizophrenia. ${ }^{211,212}$

Hebbian plasticity mechanisms appear to be modulated by sex-specific neurosteroids in animals. ${ }^{213,214}$ In particular, estradiol, allopregnanolone and related endogenous neurosteroids serve to reduce intrinsic neuronal excitability through various mechanisms. ${ }^{215}$ Provided that such

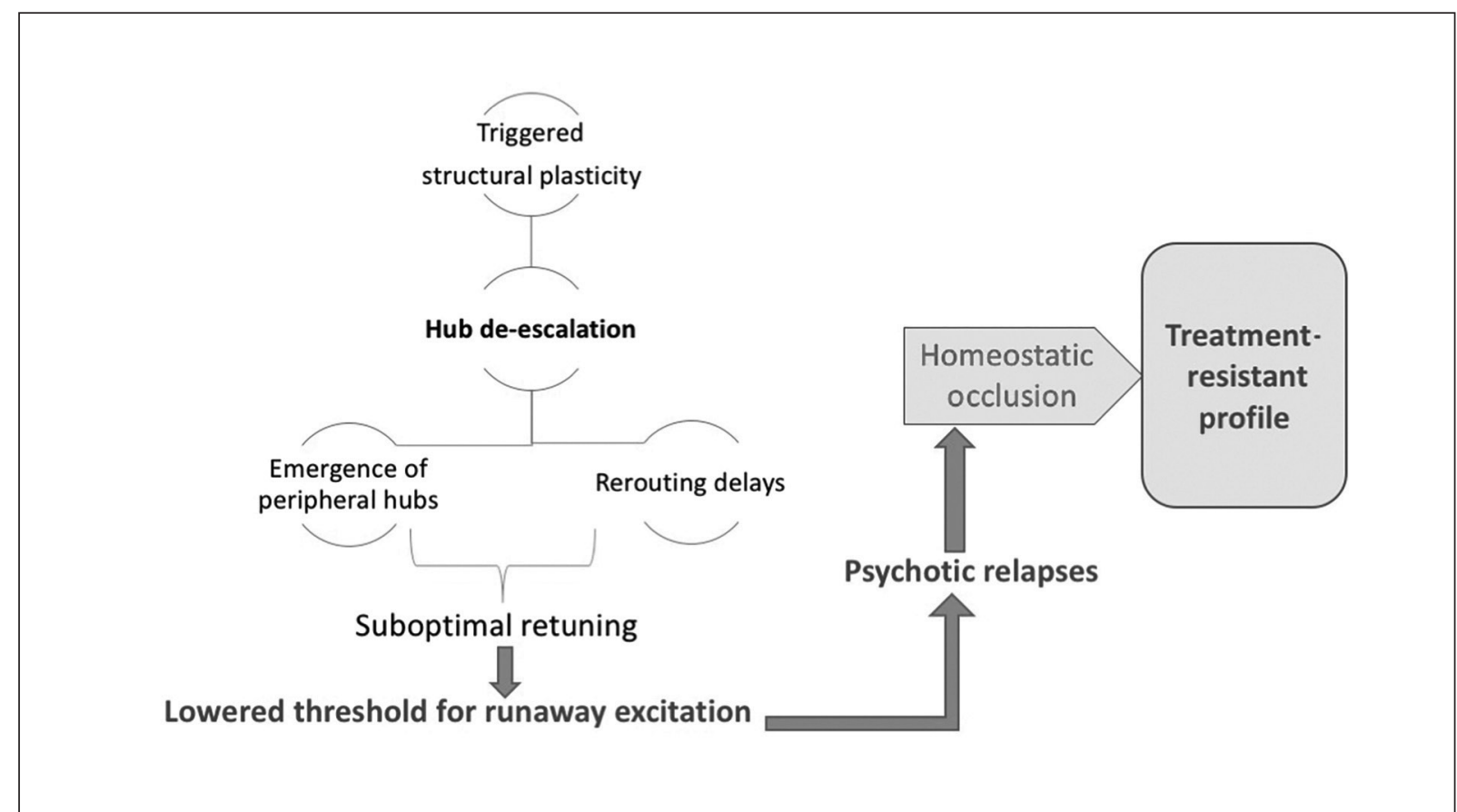

Fig. 6: Saturation of system stabilization. Hub de-escalation results in a suboptimally retuned system that is prone to runaway excitation, even with milder doses of psychosis-inducing triggers. Recurrent relapses exhaust the structural plasticity through dendritic spine elimination, leading to a state of homeostatic occlusion. This is associated with a treatment-resistant state, in which interventions that act primarily by enhancing functional plasticity are no longer effective. 
sex-specific mechanisms are preserved in people who later develop schizophrenia, the occurrence of the runaway excitation necessary for persistent psychosis and subsequent attempts contributing to grey matter loss must be less likely, taking longer to be established in women. ${ }^{216}$

\section{Compatibility with emerging observations}

Multiple lines of evidence support the various postulates that form the building blocks of inefficient neural system stabilization. A large body of evidence emerging from transcranial magnetic stimulation studies support the aberrations in plasticity mechanisms in schizophrenia. ${ }^{217-221}$ Graph-theory-based accounts using data from multiple neuroimaging modalities point to a subtle randomization of the topology of brain networks in schizophrenia despite the preservation of the sparse but efficient small-world structure of connectional architecture; ${ }^{101,179,222,223}$ this effect is anticipated if the core hubs lose their prominence and peripheral hubs emerge in an attempt to restore the sparse connectivity. ${ }^{224}$

Further, excess microglial activity, which is suspected to contribute to grey matter reduction in schizophrenia, ${ }^{225}$ can also lead to homeostatic synaptic elimination. ${ }^{226}$

\section{Genetic observations}

Inefficient neural system stabilization, characterized by a tilt from functional homeostatic plasticity to structural plasticity, is compatible with many emerging observations that link inflammatory processes with psychosis. Genome-wide association studies now point to a dysregulation of synaptic glutamatergic function ${ }^{227}$ and inflammatory mediators in schizophrenia. ${ }^{228,229}$ In the major histocompatibility complex, the variations in the complement cascade appear to be the most prominent genetic abnormality associated with schizophrenia. ${ }^{229}$ Complement cascade is dubbed the "masterful homeostatic regulator" of synaptic plasticity. ${ }^{230}$ Various products of this cascade are involved in tagging the appropriate synapses to be eliminated during normal development. ${ }^{231}$ Several other genetic loci implicated in psychotic disorders also point to mechanisms of homeostatic synaptic plasticity. ${ }^{232}$ In addition to this polygenic risk, the less common but more penetrant copy number variations converge specifically "onto a coherent biological pathway at the synapse, with a specific role in plasticity." ${ }^{\prime 233}$ In addition, genetic animal models that mimic various well-validated aspects of the schizophrenia phenotype converge on aberrant functional plasticity. ${ }^{234}$ Taken together, there is compelling evidence for the genetic basis of schizophrenia to converge on the regulation of glutamatergic synaptic plasticity.

\section{$\gamma$-Aminobutyric acid and the glutamate system}

A comprehensive review of postmortem studies suggested that the major contributor to grey matter volumetric loss in schizophrenia is synaptic regression involving glutamatergic excitatory synapses. ${ }^{110,235}$ On the other hand, functional deficits related to reduced GAD67 enzyme levels, rather than actual loss of parvalbumin-containing interneurons, are now well established in patients with schizophrenia. ${ }^{236}$ Deficiency in the GAD67 system does not appear to be a direct result of neurotransmitter dysfunction, ${ }^{237}$ but it may indicate the failure of a key functional homeostatic process that responds to excitatory synaptic activity; ${ }^{153,238-240}$ this weakening of inhibitory plasticity and subsequent connectome instability may serve to tilt the balance in favour of excitatory synaptic elimination in schizophrenia. ${ }^{241}$ This is consistent with our proposed model of inefficient neural system stabilization.

Glutamatergic concentration measured using magnetic resonance spectroscopy appears to be elevated during the early phase of illness but reduces during the course of illness, and this relates to grey matter loss at distal sites..$^{75,242,243}$ The hallmarks of excitotoxic cell damage due to excess glutamate, if present, is yet to be demonstrated in schizophrenia, ${ }^{244}$ but postmortem studies point to reduced glutamatergic dendritic spines and reduced biological coordination between glutamatergic signalling and synaptic structure. $^{245,246}$ The current model of inefficient system stabilization predicts that in early stages, higher levels of glutamate signal can be found in the loci of hyperconnectivity and anomalously increased neural activity, whereas lower levels of glutamate signal should accompany grey matter loss in schizophrenia, especially in later stages of illness, with excitatory synapses undergoing structural elimination. While several studies are in agreement, , $^{6,75,242,247,248}$ opposite results also exist. ${ }^{249}$ Cautious interpretation is required, because it is unclear how much of spectroscopic glutamate refers to synaptic activity.

The proposed notion of inefficient neural system stabilization in schizophrenia is in line with emerging literature on aberrant plasticity mechanisms, genetic observations about inflammation and aberrant glutamatergic signalling.

\section{Compatibility with current theories}

Dopamine occupies a central position in the current treatments of psychosis; midbrain dopaminergic pathways play a central role in network-level disruptions in schizophrenia. ${ }^{250}$ Dopaminergic receptors are concentrated on dendritic spines and play a key permissive role in modulating synaptic plasticity and associative learning. ${ }^{251}$ The hypothesis expounded in this review draws from existing accounts of associative learning, and so is broadly consistent with the models based on deficiencies in reinforcement learning and prediction error. ${ }^{252-258}$ Invoking disrupted plasticity as an explanation for psychotic disorders itself is not new. Stephan and colleagues posit that NMDA hypofunction is the key aspect of the plasticity defect seen in schizophrenia. ${ }^{259}$ One of the central tenets of this postulate is the ketamine model of schizophrenia. Ketamine mimics many acute symptoms of a psychotic episode, but it does not reproduce the features seen in established schizophrenia. ${ }^{260,261}$ Goto and colleagues ${ }^{262}$ highlighted the plasticity mechanisms of the prefrontal cortex and how they could be disrupted in schizophrenia. Keshavan and colleagues ${ }^{263}$ assembled a large body of evidence to argue that the positive symptoms of schizophrenia 
can be explained by hyperplasticity and negative symptoms by hypoplasticity, either being a compensatory response to the other. More recently, Forsyth and Lewis ${ }^{264}$ posited that the consequences of impaired synaptic plasticity during development explains the emergence of clinical symptoms of schizophrenia. System stabilization processes operating at the synaptic and macro-connectomic level are not invoked in the models proposed above. ${ }^{262-264}$

A recent proposition highlights the role of homeostatic compensations in the putative excitation-inhibition imbalance that starts with primary glutamatergic abnormality in schizophrenia. ${ }^{265}$ In contrast, the current model takes an agnostic view on the primacy of neurochemical abnormality. I propose that various disruptions in associative learning can invoke the earliest symptoms of psychosis, but that the core dysfunction in established schizophrenia lies in the homeostatic aspect of plasticity that is likely to involve primarily NMDA, but can also occur as a result of disruptions in other endogenous systems, such as the endocannabinoid pathways. By placing the emphasis on the homeostatic aspect of plasticity, the current hypothesis attempts to explain the continuum and course of schizophrenia rather than the acute phase of symptom appearance (Fig. 7). I also provide a framework that incorporates the emerging literature on connectomics, plasticity deficits, neuroprogression and inflammation and addresses distinct aspects of populationlevel variation in the course and outcome of primary psychotic disorders.

\section{The role of the individual in neural system stabilization}

Homeostatic processes operate at various levels to maintain the relative constancy of the regulated variables, and scale up from an intracellular to a societal milieu through hierarchical feedback processes. ${ }^{140}$ For example, intracellular sodium balance can be eventually traced up to the predominance of human settlements close to water sources. Claude Bernard, one of the earliest proponents of the idea of homeostasis, maintains that the objective of this regulated constancy is to maintain the "harmonious whole."266 This whole is often considered to be the "free and individual self" ${ }^{\prime \prime 39}$ when studying biological systems, but it could refer to any of the higher levels of a self-organizing entity. Another important distinction between conventional homeostatic pathways and a self-organizing system is that an agent of control is not required to "sniff out" the perturbations in a self-organizing system. ${ }^{141}$

Does this mean an individual cannot have wilful control over the process of system stabilization? On the contrary: observations from clinical practice suggest that individuals have an intended control over the course of psychotic disorders. A strong sense of self, ${ }^{267}$ along with an internal locus of control of the illness, ${ }^{268}$ appear to be critical factors for recovery in psychotic disorders.

Damasio and Damasio argue that the feed-forward pathways of homeostasis give rise to conscious feeling states, which serve as "informative regulatory interfaces." 269 This mental aspect is an evolutionary advance that turns the individual organism into an agent of its own regulation. The "feeling state" generated by the connectome overload is likely to drive an individual to exert agentic guidance on system stabilization. Provided that the tools to correct (i.e., the physico-chemical apparatus for system stabilization) are accessible, individual efforts should hasten the restoration of the steady state. However, given the freedom of operation and societal influence, feeling-driven adjustments may not always be chosen to restore the perturbed system to its optimal state. ${ }^{269}$ This imperfection introduces another layer of heterogeneity in the prognostic trajectory of psychotic disorders. ${ }^{270}$

\section{Grades of psychosis}

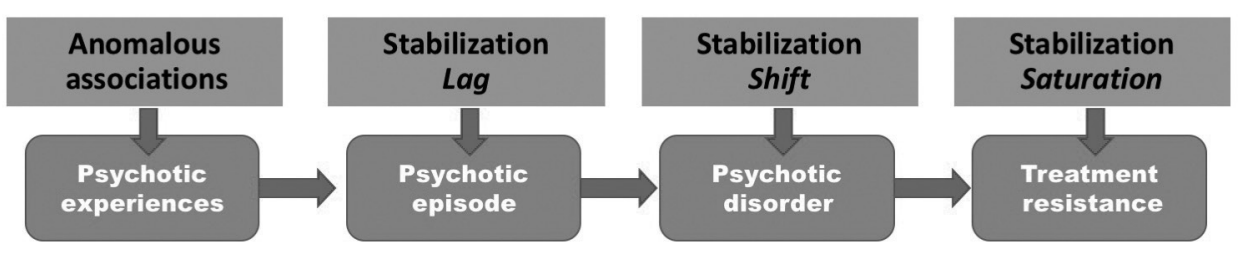

Aberrant topological self-stabilization

Fig. 7: Neural system stabilization and grades of psychosis. The degree of impairment in the homeostatic process of topological neural system stabilization determines whether an episode of psychosis resolves fully, relapses repeatedly or fails to respond to currently prescribed interventions. 
What is the nature of the feeling state that results from connectome overload? To answer the question, one must consider (1) the informative utility of the feeling state (i.e., the feeling must signal an adjustment that the organism is required to make in order to restore the system) and (2) the regulatory value (i.e., the feeling must serve to reduce further exposure to the triggers that perturb the system). It is tempting to speculate that secondary (or phasic ${ }^{271}$ ) negative symptoms (e.g., the feeling that nothing is pleasurable anymore; anhedonia) $)^{272}$ could signal the individual to reduce sensory, social and chemical stimuli that increase the likelihood of hyperconnectivity and further connectome overload.

The neural system stabilization theory proposed here allows for conscious agentic guidance of an individual in homeostatic processes, and raises interesting prospects regarding the wilful control of recovery in psychotic disorders (see Appendix 1 on the issue of insight and neural system stabilization, available at jpn.ca/180038-a1).

\section{Predictions, limitations and further questions}

Physiologic disruptions in neural processes related to learning based on temporal contingency are likely to be nonspecific to schizophrenia and will be shared not only by other psychotic disorders, but also by healthy people with psychosis-like experiences. But patients with schizophrenia are more likely to have specific disruptions in the system stabilization mechanisms that favour structural over functional plasticity. This vulnerability, if present from early life, could increase the risk of structural neurodevelopmental aberrations, various forms of intellectual and learning deficits even in the absence of psychosis (e.g., in siblings, or in premorbid stages ${ }^{273}$ ). But after the onset of symptoms, more extensive structural changes would be limited to those with inefficient system stabilization. As a result, morphometric changes may not be directly related to genetic liability for disease expression. But because tissue loss is related to neural plasticity, reversal of these structural deficits is possible. ${ }^{65}$ Identifying people at risk of more severe forms of psychosis and offering treatments that reduce or delay progressive synaptic changes at early stages may have a true disease-modifying effect. There are some promising venues in this respect. ${ }^{274-277}$ Established postonset grey matter loss is the sign of a "steady state," albeit an imperfect one, that serves to induce further relapses. Reversal of deficits may require some disruption of this suboptimal steady state to enable the introduction of alternate means of neural system stability. To make therapeutic progress in established cases, it would be important to know how to safely carry out such topological restoration. Emerging neuromodulation approaches provide some promising leads. ${ }^{219}$

Given the heterogeneity of the currently accepted construct of schizophrenia, it is unlikely that any single theory could fit the multitude of observations pertaining to this disease. In particular, the notion of inefficient system stabilization does not offer causal explanations; it merely offers a mechanistic framework in which the operations of several causal agents could converge. In line with many other prevailing hypotheses, the current framework offers a better explanation for the course of positive symptoms; there is a greater degree of uncertainty surrounding the nature of relapse and the resolution of negative symptoms and thought disorder in schizophrenia. Further, the inefficient system stabilization model is inadequate for explaining the heterogeneity in symptoms of schizophrenia. Finally, the proposed theory does not provide a single index of a homeostatically regulated variable that can capture the inefficient system stabilization that can occur in all patients. Instead, it raises the suggestion that aberrations in various indicators representing the extant pathways of intrinsic plasticity and structural plasticity can be brought together to characterize a substantial number of patients with poor outcome.

Aberrations in homeostatic plasticity have been suspected in many neuropsychiatric disorders (see Appendix 1 on the issue of bipolar disorder and neural system stabilization). ${ }^{155,232,262,278,279}$ Future studies aimed at discovering the aspects of this disruption that is specific to schizophrenia are required to fully understand the molecular pathways that can be targeted for treatment. If experimental models of disrupted homeostatic plasticity fail to mimic the true phenotype of schizophrenia despite the presence of conditions that disrupt associative plasticity, the theory proposed here could be refuted. To my knowledge, there is a striking lack of studies in patients who have recovered after a single psychotic episode, as well as longitudinal studies on connectome topology. Such studies are essential to test the premises of the neural system stabilization theory (Table 2; see Appendix 1 on the issue of insight and neural system stabilization).

Table 2: Experimental approaches to test the neural system stabilization theory of schizophrenia

\begin{tabular}{|c|c|}
\hline Postulates & Approaches to test \\
\hline $\begin{array}{l}\text { Shift from functional to structural } \\
\text { plasticity induces dendritic spine } \\
\text { reduction }\end{array}$ & $\begin{array}{l}\text { Animal models of disrupted } \\
\text { homeostatic plasticity, when } \\
\text { subjected to repeated associative } \\
\text { learning, would mimic the structural } \\
\text { phenotype of schizophrenia }\end{array}$ \\
\hline $\begin{array}{l}\text { Focal hyperconnectivity predates } \\
\text { diffuse hypoconnectivity in } \\
\text { psychotic disorders }\end{array}$ & $\begin{array}{l}\text { Longitudinal imaging from } \\
\text { unmedicated first episode of } \\
\text { psychosis to the postpsychotic } \\
\text { stage would show shifting patterns } \\
\text { of connectivity in patients } \\
\text { responding to treatment }\end{array}$ \\
\hline $\begin{array}{l}\text { Hub de-escalation occurs after first } \\
\text { episode of psychosis }\end{array}$ & $\begin{array}{l}\text { Patients with schizophrenia-like } \\
\text { phenotype would show progressive } \\
\text { reduction of hubness of core } \\
\text { nodes, emergence of peripheral } \\
\text { hubs and grey matter reduction in } \\
\text { hub regions }\end{array}$ \\
\hline $\begin{array}{l}\text { Lag of neural system stabilization } \\
\text { in patients with a single psychotic } \\
\text { episode }\end{array}$ & $\begin{array}{l}\text { Patients with single psychotic } \\
\text { episodes with full recovery would } \\
\text { lack postpsychotic morphological } \\
\text { and connectomic changes }\end{array}$ \\
\hline $\begin{array}{l}\text { Occlusion of topological } \\
\text { homeostasis in treatment-resistant } \\
\text { subjects }\end{array}$ & $\begin{array}{l}\text { Lack of learning-induced changes } \\
\text { in network connectivity in patients } \\
\text { with treatment resistance }\end{array}$ \\
\hline
\end{tabular}




\section{Conclusion}

I speculate that psychosis, as seen in clinical practice, is not a disorder of any single neurotransmitter system or a particular brain network; instead, it is a disorder of cerebral acclimatization to new learning. An important aspect of this theory is that there is an intrinsic antipsychotic defence mechanism that promotes system stabilization in the human brain; this mechanism is built on the balancing act between neural activity and connectivity that is essential for learning statistical regularities in our immediate environment. Restoration of this intrinsic system stabilization can reverse many features of long-term psychotic illnesses. Critical timing of interventions, combined with approaches that provoke and redirect the pathways of neural network stability, may be required to realize this goal.

Acknowledgement: The author gratefully acknowledges Dr. Ross Norman for initial discussions; Prof. Tim Crow (Oxford) for reviewing this hypothesis and commenting on several aspects of this manuscript; and Dr. Ridha Joober and the attendees of CCNP Annual Meeting in Kingston, Ont., in June 2017, for stimulating questions that led to revisions of this work.

Affiliations: From the Department of Psychiatry and Robarts Research Institute, University of Western Ontario and Lawson Health Research Institute, London, Ont., Canada.

Funding: L. Palaniyappan's work is supported by the Canadian Institute of Health Research (Foundation Grant 375104), the Bucke Family Fund and the Academic Medical Organization of South Western Ontario.

Competing interests: L. Palaniyappan reports personal fees from Janssen Canada, Otsuka Canada, SPMM Course Limited, UK, and the Canadian Psychiatric Association; book royalties from Oxford University Press; investigator-initiated educational grants from Sunovion, Janssen Canada and Otsuka Canada; and travel support from Boehringer Ingelheim and Magstim Limited, outside the submitted work. In the last 3 years, L. Palaniyappan and/or his spouse have held shares in Shire Pharmaceuticals and GlaxoSmithKline in their pension funds for values less than US $\$ 10000$. L. Palaniyappan joined the JPN editorial board in October 2019, after the current work was published online.

\section{References}

1. Macdonald AW, Schulz SC. What we know: findings that every theory of schizophrenia should explain. Schizophr Bull 2009;35:493-508.

2. Tandon R, Keshavan MS, Nasrallah HA. Schizophrenia, "just the facts": what we know in 2008 part 1: overview. Schizophr Res 2008;100:4-19.

3. McGrath JJ, Saha S, Al-Hamzawi AO, et al. Age of onset and lifetime projected risk of psychotic experiences: cross-national data from the World Mental Health Survey. Schizophr Bull 2016;42:933-41.

4. van Os J, Linscott RJ, Myin-Germeys I, et al. A systematic review and meta-analysis of the psychosis continuum: evidence for a psychosis proneness-persistence-impairment model of psychotic disorder. Psychol Med 2009;39:179-95.

5. Linscott RJ, van Os J. An updated and conservative systematic review and meta-analysis of epidemiological evidence on psychotic experiences in children and adults: on the pathway from proneness to persistence to dimensional expression across mental disorders. Psychol Med 2013;43:1133-49.

6. Zammit S, Kounali D, Cannon M, et al. Psychotic experiences and psychotic disorders at age 18 in relation to psychotic experiences at age 12 in a longitudinal population-based cohort study. Am J Psychiatry 2013;170:742-50.
7. Cannon TD, Yu C, Addington J, et al. An individualized risk calculator for research in prodromal psychosis. Am J Psychiatry 2016; 173:980-8.

8. Fusar-Poli P, Bonoldi I, Yung AR, et al. Predicting psychosis: metaanalysis of transition outcomes in individuals at high clinical risk. Arch Gen Psychiatry 2012;69:220-9.

9. Nelson B, Yuen H, Wood SJ, et al. Long-term follow-up of a group at ultra high risk ("prodromal") for psychosis: the pace 400 study. JAMA Psychiatry 2013;70:793-802.

10. Morgan C, Abdul-Al R, Lappin JM, et al. Clinical and social determinants of duration of untreated psychosis in the AESOP firstepisode psychosis study. Br J Psychiatry J Ment Sci 2006;189:446-52.

11. Albert N, Melau M, Jensen H, et al. The effect of duration of untreated psychosis and treatment delay on the outcomes of prolonged early intervention in psychotic disorders. Npj Schizophr 2017;3:34.

12. Farooq S. Is acute and transient psychotic disorder (ATPD) mini schizophrenia? The evidence from phenomenology and epidemiology. Psychiatr Danub 2012;24(Suppl 3):S311-5.

13. Hambrecht $\mathrm{M}$, Häfner H. "Trema, apophany, apocalypse": Is Conrad's phase model empirically founded? Fortschr Neurol Psychiatr 1993:61:418-23.

14. Mishara AL. Klaus Conrad (1905-1961): delusional mood, psychosis, and beginning schizophrenia. Schizophr Bull 2010;36:9-13.

15. Stanton B, David AS. First-person accounts of delusions. Psychiatrist 2000;24:333-6.

16. Paolini E, Moretti P, Compton MT. Delusions in first-episode psychosis: principal component analysis of twelve types of delusions and demographic and clinical correlates of resulting domains. Psychiatry Res 2016;243:5-13.

17. Chadwick PK. Peer-professional first-person account: schizophrenia from the inside - phenomenology and the integration of causes and meanings. Schizophr Bull 2007;33:166-73.

18. Chapman RK. First person account: eliminating delusions. Schizophr Bull 2002;28:545-53

19. Powell J. First person account: paranoid schizophrenia - a daughter's story. Schizophr Bull 1998;24:175-7.

20. Alvarez-Jimenez M, Gleeson JF, Henry LP, et al. Prediction of a single psychotic episode: a 7.5-year, prospective study in firstepisode psychosis. Schizophr Res 2011;125:236-46.

21. Fusar-Poli P, Cappucciati M, Bonoldi I, et al. Prognosis of brief psychotic episodes: a meta-analysis. JAMA Psychiatry 2016;73:211-20.

22. Manchanda R, Norman RMG, Malla AK, et al. Persistent psychoses in first episode patients. Schizophr Res 2005;80:113-6.

23. Queirazza F, Semple DM, Lawrie SM. Transition to schizophrenia in acute and transient psychotic disorders. Br J Psychiatry 2014; 204:299-305.

24. Wiersma D, Nienhuis FJ, Slooff CJ, et al. Natural course of schizophrenic disorders: a 15-year followup of a Dutch incidence cohort. Schizophr Bull 1998;24:75-85.

25. Correll CU, Smith CW, Auther AM, et al. Predictors of remission, schizophrenia, and bipolar disorder in adolescents with brief psychotic disorder or psychotic disorder not otherwise specified considered at very high risk for schizophrenia. J Child Adolesc Psychopharmacol 2008;18:475-90.

26. Bockoven JS. Moral treatment in American psychiatry. Springer Pub. Co.; 1956

27. Agid O, Kapur S, Arenovich T, et al. Delayed-onset hypothesis of antipsychotic action: a hypothesis tested and rejected. Arch Gen Psychiatry 2003;60:1228-35.

28. Emsley R, Rabinowitz J, Medori R. Time course for antipsychotic treatment response in first-episode schizophrenia. Am J Psychiatry 2006;163:743-5

29. Kinon BJ, Chen L, Ascher-Svanum H, et al. Predicting response to atypical antipsychotics based on early response in the treatment of schizophrenia. Schizophr Res 2008;102:230-40.

30. Norman RMG, Manchanda R, Windell D. The prognostic significance of early remission of positive symptoms in first treated psychosis. Psychiatry Res 2014;218:44-7.

31. Samara MT, Leucht C, Leeflang MM, et al. Early improvement as a predictor of later response to antipsychotics in schizophrenia: a diagnostic test review. Am J Psychiatry 2015;172:617-29.

32. Sacks MH, Carpenter WT Jr, et al. Recovery from delusions: three phases documented by patient's interpretation of research procedures. Arch Gen Psychiatry 1974;30:117-20. 
33. Addington J, Addington D. Positive and negative symptoms of schizophrenia. Their course and relationship over time. Schizophr Res 1991:5:51-9.

34. Arndt S, Andreasen NC, Flaum M, et al. A longitudinal study of symptom dimensions in schizophrenia. Prediction and patterns of change. Arch Gen Psychiatry 1995;52:352-60.

35. Buchanan RW. Persistent negative symptoms in schizophrenia: an overview. Schizophr Bull 2007;33:1013-22.

36. Emsley R, Chiliza B, Asmal L, et al. The nature of relapse in schizophrenia. BMC Psychiatry 2013;13:50.

37. Leucht S, Tardy M, Komossa K, et al. Antipsychotic drugs versus placebo for relapse prevention in schizophrenia: a systematic review and meta-analysis. Lancet 2012;379:2063-71.

38. Remington G, Foussias G, Agid O, et al. The neurobiology of relapse in schizophrenia. Schizophr Res 2014;152:381-90.

39. Zipursky RB, Menezes NM, Streiner DL. Risk of symptom recurrence with medication discontinuation in first-episode psychosis: a systematic review. Schizophr Res 2014;152:408-14.

40. Appelbaum PS, Robbins PC, Vesselinov R. Persistence and stability of delusions over time. Compr Psychiatry 2004;45:317-24.

41. Sinha VK, Chaturvedi SK. Consistency of delusions in schizophrenia and affective disorder. Schizophr Res 1990;3:347-50.

42. Alvarez-Jimenez M, O'Donoghue B, Thompson A, et al. Beyond clinical remission in first episode psychosis: thoughts on antipsychotic maintenance vs. guided discontinuation in the functional recovery era. CNS Drugs 2016;30:357-68.

43. Harrow M, Jobe TH. Factors involved in outcome and recovery in schizophrenia patients not on antipsychotic medications: a 15-year multifollow-up study. J Nerv Ment Dis 2007;195:406-14

44. Wunderink L, Nieboer RM, Wiersma D, et al. Recovery in remitted first-episode psychosis at 7 years of follow-up of an early dose reduction/discontinuation or maintenance treatment strategy: long-term follow-up of a 2-year randomized clinical trial. JAMA Psychiatry 2013;70:913-20.

45. Ellison-Wright I, Glahn DC, Laird AR, et al. The anatomy of firstepisode and chronic schizophrenia: an anatomical likelihood estimation meta-analysis. Am J Psychiatry 2008;165:1015-23.

46. Glahn DC, Laird AR, Ellison-Wright I, et al. Meta-analysis of gray matter anomalies in schizophrenia: application of anatomic likelihood estimation and network analysis. Biol Psychiatry 2008;64:774-81.

47. Chan RCK, Di X, McAlonan GM, et al. Brain anatomical abnormalities in high-risk individuals, first-episode, and chronic schizophrenia: an activation likelihood estimation meta-analysis of illness progression. Schizophr Bull 2011;37:177-88.

48. Fusar-Poli P, Borgwardt S, Crescini A, et al. Neuroanatomy of vulnerability to psychosis: a voxel-based meta-analysis. Neurosci Biobehav Rev 2011;35:1175-85.

49. Bhojraj TS, Sweeney JA, Prasad KM, et al. Progressive alterations of the auditory association areas in young non-psychotic offspring of schizophrenia patients. J Psychiatr Res 2011;45:205-12.

50. Fusar-Poli P, Smieskova R, Serafini G, et al. Neuroanatomical markers of genetic liability to psychosis and first episode psychosis: a voxelwise meta-analytical comparison. World J Biol Psychiatry 2014;15:219-28.

51. Palaniyappan L, Balain V, Liddle PF. The neuroanatomy of psychotic diathesis: a meta-analytic review. J Psychiatr Res 2012;46:1249-56.

52. Fusar-Poli P, Smieskova R, Kempton MJ, et al. Progressive brain changes in schizophrenia related to antipsychotic treatment? A meta-analysis of longitudinal MRI studies. Neurosci Biobehav Rev 2013;37:1680-91.

53. Vita A, Peri LD, Deste G, et al. Progressive loss of cortical gray matter in schizophrenia: a meta-analysis and meta-regression of longitudinal MRI studies. Transl Psychiatry 2012;2:e190.

54. Andreasen NC, Nopoulos P, Magnotta V, et al. Progressive brain change in schizophrenia: a prospective longitudinal study of firstepisode schizophrenia. Biol Psychiatry 2011;70:672-9.

55. Van Haren NE, Cahn W, Hulshoff Pol HE, et al. Confounders of excessive brain volume loss in schizophrenia. Neurosci Biobehav Rev 2013;37:2418-23.

56. Kempton MJ, Stahl D, Williams SCR, et al. Progressive lateral ventricular enlargement in schizophrenia: a meta-analysis of longitudinal MRI studies. Schizophr Res 2010;120:54-62.

57. Ota M, Obu S, Sato N, et al. Progressive brain changes in schizophrenia: a 1-year follow-up study of diffusion tensor imaging. Acta Neuropsychiatr 2009;21:301-7.
58. Andreasen NC, Liu D, Ziebell S, et al. Relapse duration, treatment intensity, and brain tissue loss in schizophrenia: a prospective longitudinal MRI study. Am J Psychiatry 2013;170:609-15.

59. Mitelman SA, Canfield EL, Newmark RE, et al. Longitudinal assessment of gray and white matter in chronic schizophrenia: a combined diffusion-tensor and structural magnetic resonance imaging study. Open Neuroimaging J 2009;3:31-47.

60. Rosa PGP, Zanetti MV, Duran FLS, et al. What determines continuing grey matter changes in first-episode schizophrenia and affective psychosis? Psychol Med 2015;45:817-28.

61. Battistella G, Fornari E, Annoni J-M, et al. Long-term effects of cannabis on brain structure. Neuropsychopharmacology 2014;39:2041-8.

62. Zipursky RB, Reilly TJ, Murray RM. The myth of schizophrenia as a progressive brain disease. Schizophr Bull 2013;39:1363-72

63. Ho B-C, Andreasen NC, Ziebell S, et al. Long-term antipsychotic treatment and brain volumes: a longitudinal study of first-episode schizophrenia. Arch Gen Psychiatry 2011;68:128-37.

64. Roiz-Santiañez R, Suarez-Pinilla P, Crespo-Facorro B. Brain structural effects of antipsychotic treatment in schizophrenia: a systematic review. Curr Neuropharmacol 2015;13:422-34.

65. Eack SM, Hogarty GE, Cho RY, et al. Neuroprotective effects of cognitive enhancement therapy against gray matter loss in early schizophrenia: results from a 2-year randomized controlled trial. Arch Gen Psychiatry 2010;67:674-82.

66. Isaac C, Januel D. Neural correlates of cognitive improvements following cognitive remediation in schizophrenia: a systematic review of randomized trials. Socioaffect Neurosci Psychol 2016;6:30054.

67. Malchow B, Keeser D, Keller K, et al. Effects of endurance training on brain structures in chronic schizophrenia patients and healthy controls. Schizophr Res 2016;173:182-91.

68. Pajonk F-G, Wobrock T, Gruber O, et al. Hippocampal plasticity in response to exercise in schizophrenia. Arch Gen Psychiatry 2010; 67:133-43

69. Aoyama N, Théberge J, Drost DJ, et al. Grey matter and social functioning correlates of glutamatergic metabolite loss in schizophrenia. Br J Psychiatry J Ment Sci 2011;198:448-56.

70. Asami T, Bouix S, Whitford TJ, et al. Longitudinal loss of gray matter volume in patients with first-episode schizophrenia: DARTEL automated analysis and ROI validation. Neuroimage 2012; 59:986-96.

71. Farrow TFD, Whitford TJ, Williams LM, et al. Diagnosis-related regional gray matter loss over two years in first episode schizophrenia and bipolar disorder. Biol Psychiatry 2005;58:713-23.

72. Gutiérrez-Galve L, Chu EM, Leeson VC, et al. A longitudinal study of cortical changes and their cognitive correlates in patients followed up after first-episode psychosis. Psychol Med 2015;45:205-16.

73. Mané A, Falcon C, Mateos JJ, et al. Progressive gray matter changes in first episode schizophrenia: a 4-year longitudinal magnetic resonance study using VBM. Schizophr Res 2009;114:136-43.

74. Olabi B, Ellison-Wright I, McIntosh AM, et al. Are there progressive brain changes in schizophrenia? A meta-analysis of structural magnetic resonance imaging studies. Biol Psychiatry 2011;70:88-96.

75. Théberge J, Williamson KE, Aoyama N, et al. Longitudinal greymatter and glutamatergic losses in first-episode schizophrenia. Br J Psychiatry J Ment Sci 2007;191:325-34.

76. Guo JY, Huhtaniska S, Miettunen J, et al. Longitudinal regional brain volume loss in schizophrenia: relationship to antipsychotic medication and change in social function. Schizophr Res 2015;168:297-304.

77. Lee S-H, Niznikiewicz M, Asami T, et al. Initial and progressive gray matter abnormalities in insular gyrus and temporal pole in first-episode schizophrenia contrasted with first-episode affective psychosis. Schizophr Bull 2016;42: 790-801.

78. Buckner RL, Sepulcre J, Talukdar T, et al. Cortical hubs revealed by intrinsic functional connectivity: mapping, assessment of stability, and relation to Alzheimer's disease. J Neurosci 2009;29:1860-73.

79. van den Heuvel MP, Sporns O. Rich-club organization of the human connectome. J Neurosci Off J Soc Neurosci 2011;31:15775-86.

80. Collin G, Sporns O, Mandl RCW, et al. Structural and functional aspects relating to cost and benefit of rich club organization in the human cerebral cortex. Cereb Cortex 1991;2014:2258-67.

81. Stam CJ. Modern network science of neurological disorders. Nat Rev Neurosci 2014;15:683-95.

82. Crossley NA, Mechelli A, Scott J, et al. The hubs of the human connectome are generally implicated in the anatomy of brain disorders. Brain J Neurol 2014;137:2382-95. 
83. Andreasen NC. The lifetime trajectory of schizophrenia and the concept of neurodevelopment. Dialogues Clin Neurosci 2010;12: 409-15.

84. Fatemi SH, Folsom TD. The neurodevelopmental hypothesis of schizophrenia, revisited. Schizophr Bull 2009;35:528-48.

85. Murray RM, Lewis SW. Is schizophrenia a neurodevelopmental disorder? Br Med J (Clin Res Ed) 1987;295:681-2.

86. Piper M, Beneyto M, Burne THJ, et al. The neurodevelopmental hypothesis of schizophrenia: convergent clues from epidemiology and neuropathology. Psychiatr Clin North Am 2012;35:571-84.

87. Rapoport JL, Giedd JN, Gogtay N. Neurodevelopmental model of schizophrenia: update 2012. Mol Psychiatry 2012;17:1228-38.

88. Weinberger DR. Implications of normal brain development for the pathogenesis of schizophrenia. Arch Gen Psychiatry 1987;44:660-9.

89. DeLisi LE. The concept of progressive brain change in schizophrenia: implications for understanding schizophrenia. Schizophr Bull 2008;34:312-21.

90. Hulshoff Pol HE, Kahn RS. What happens after the first episode? A review of progressive brain changes in chronically ill patients with schizophrenia. Schizophr Bull 2008;34:354-66.

91. Lieberman JA. Is schizophrenia a neurodegenerative disorder? A clinical and neurobiological perspective. Biol Psychiatry 1999; 46:729-39.

92. Pantelis C, Velakoulis D, McGorry PD, et al. Neuroanatomical abnormalities before and after onset of psychosis: a cross-sectional and longitudinal MRI comparison. Lancet 2003;361:281-8.

93. Falkai P, Rossner MJ, Schulze TG, et al. Kraepelin revisited: schizophrenia from degeneration to failed regeneration. Mol Psychiatry 2015;20:671-6.

94. Keshavan MS. Development, disease and degeneration in schizophrenia: a unitary pathophysiological model. J Psychiatr Res 1999; 33:513-21.

95. Kochunov P, Hong LE. Neurodevelopmental and neurodegenerative models of schizophrenia: white matter at the center stage. Schizophr Bull 2014;40:721-8.

96. Pantelis C, Yücel M, Wood SJ, et al. Structural brain imaging evidence for multiple pathological processes at different stages of brain development in schizophrenia. Schizophr Bull 2005;31:672-96.

97. Woods BT. Is schizophrenia a progressive neurodevelopmental disorder? Toward a unitary pathogenetic mechanism. Am J Psychiatry 1998;155:1661-70.

98. Hedman AM, van Haren NEM, Schnack HG, et al. Human brain changes across the life span: a review of 56 longitudinal magnetic resonance imaging studies. Hum Brain Mapp 2012;33:1987-2002.

99. Tamnes CK, Walhovd KB, Dale AM, et al. Brain development and aging: overlapping and unique patterns of change. Neuroimage 2013;68:63-74.

100. Schnack HG, van Haren NEM, Nieuwenhuis M, et al. Accelerated brain aging in schizophrenia: a longitudinal pattern recognition study. Am J Psychiatry 2016;173:607-16.

101. Collin G, Turk E, van den Heuvel MP. Connectomics in schizophrenia: from early pioneers to recent brain network findings. Biol Psychiatry Cogn Neurosci Neuroimaging 2016;1:199-208.

102. Coyle JT, Balu DT, Puhl MD, et al. History of the concept of disconnectivity in schizophrenia. Harv Rev Psychiatry 2016;24:80-6.

103. Gross, O. Dementia sejunctiva. In: Cutting JC, Shepherd M, editors. The clinical roots of the schizophrenia concept. Cambridge: Cambridge University Press; 1987: 35-6.

104. Lanczik M, Keil G. Carl Wernicke's localization theory and its significance for the development of scientific psychiatry. Hist Psychiatry 1991;2:171-80.

105. Bullmore ET, Frangou S, Murray RM. The dysplastic net hypothesis: an integration of developmental and dysconnectivity theories of schizophrenia. Schizophr Res 1997;28:143-56.

106. Andreasen NC, Paradiso S, O'Leary DS. "Cognitive dysmetria" as an integrative theory of schizophrenia. Schizophr Bull 1998;24: 203-18.

107. Selemon LD, Goldman-Rakic PS. The reduced neuropil hypothesis: a circuit based model of schizophrenia. Biol Psychiatry 1999:45:17-25.

108. Stephan KE, Baldeweg T, Friston KJ. Synaptic plasticity and dysconnection in schizophrenia. Biol Psychiatry 2006;59:929-39.

109. Looijestijn J, Blom JD, Aleman A, et al. An integrated network model of psychotic symptoms. Neurosci Biobehav Rev 2015;59: 238-50.
110. Bennett MR. Schizophrenia: susceptibility genes, dendritic-spine pathology and gray matter loss. Prog Neurobiol 2011;95:275-300.

111. Harrison PJ. Neuropathology of schizophrenia. Psychiatry 2005 4:18-21.

112. Pettersson-Yeo W, Allen P, Benetti S, et al. Dysconnectivity in schizophrenia: Where are we now? Neurosci Biobehav Rev 2011; 35:1110-24.

113. Ellison-Wright I, Bullmore E. Meta-analysis of diffusion tensor imaging studies in schizophrenia. Schizophr Res 2009;108:3-10.

114. Kubicki M, McCarley R, Westin C-F, et al. A review of diffusion tensor imaging studies in schizophrenia. J Psychiatr Res 2005:41:15-30.

115. Fornito A, Bullmore ET. Reconciling abnormalities of brain network structure and function in schizophrenia. Curr Opin Neurobiol 2015;30:44-50.

116. van den Heuvel MP, Scholtens LH, de Reus MA, et al. Associated microscale spine density and macroscale connectivity disruptions in schizophrenia. Biol Psychiatry 2016;80:293-301.

117. Power JD, Barnes KA, Snyder AZ, et al. Spurious but systematic correlations in functional connectivity MRI networks arise from subject motion. Neuroimage 2012;59:2142-54

118. Yang GJ, Murray JD, Repovs G, et al. Altered global brain signal in schizophrenia. Proc Natl Acad Sci U S A 2014;111:7438-43.

119. Anticevic A, Hu X, Xiao Y, et al. Early-course unmedicated schizophrenia patients exhibit elevated prefrontal connectivity associated with longitudinal change. J Neurosci Off J Soc Neurosci 2015; 35:267-86.

120. Li T, Wang Q, Zhang J, et al. Brain-wide analysis of functional connectivity in first-episode and chronic stages of schizophrenia. Schizophr Bull 2017;43:436-48.

121. Ford JM, Palzes VA, Roach BJ, et al. Visual hallucinations are associated with hyperconnectivity between the amygdala and visual cortex in people with a diagnosis of schizophrenia. Schizophr Bul 2015;41:223-32.

122. Whitfield-Gabrieli S, Thermenos HW, Milanovic S, et al. Hyperactivity and hyperconnectivity of the default network in schizophrenia and in first-degree relatives of persons with schizophrenia. Proc Natl Acad Sci U S A 2009;106:1279-84.

123. Lui S, Li T, Deng W, et al. Short-term effects of antipsychotic treatment on cerebral function in drug-naive first-episode schizophrenia revealed by "resting state" functional magnetic resonance imaging. Arch Gen Psychiatry 2010;67:783-92.

124. Carhart-Harris RL, Leech R, Erritzoe D, et al. Functional connectivity measures after psilocybin inform a novel hypothesis of early psychosis. Schizophr Bull 2013;39:1343-51.

125. Driesen NR, McCarthy G, Bhagwagar Z, et al. Relationship of resting brain hyperconnectivity and schizophrenia-like symptoms produced by the NMDA receptor antagonist ketamine in humans. Mol Psychiatry 2013;18:1199-204

126. Anticevic A, Corlett PR, Cole MW, et al. N-methyl-D-aspartate receptor antagonist effects on prefrontal cortical connectivity better model early than chronic schizophrenia. Biol Psychiatry 2015; 77:569-80.

127. Anticevic A, Gancsos M, Murray JD, et al. NMDA receptor function in large-scale anticorrelated neural systems with implications for cognition and schizophrenia. Proc Natl Acad Sci U S A 2012;109: 16720-5.

128. Höflich A, Hahn A, Küblböck M, et al. Ketamine-induced modulation of the thalamo-cortical network in healthy volunteers as a model for schizophrenia. Int J Neuropsychopharmacol 2015;18.

129. Joules R, Doyle OM, Schwarz AJ, et al. Ketamine induces a robust whole-brain connectivity pattern that can be differentially modulated by drugs of different mechanism and clinical profile. Psychopharmacology (Berl) 2015;232:4205-18.

130. Rivolta D, Heidegger T, Scheller B, et al. Ketamine dysregulates the amplitude and connectivity of high-frequency oscillations in cortical-subcortical networks in humans: evidence from restingstate magnetoencephalography-recordings. Schizophr Bull 2015;41: 1105-14.

131. Karbasforoushan H, Woodward ND. Resting-state networks in schizophrenia. Curr Top Med Chem 2012;12:2404-14.

132. Woodward ND, Rogers B, Heckers S. Functional resting-state networks are differentially affected in schizophrenia. Schizophr Res 2011;130:86-93.

133. Raichle ME, MacLeod AM, Snyder AZ, et al. A default mode of brain function. Proc Natl Acad Sci U S A 2001;98:676-82. 
134. Hillary FG, Roman CA, Venkatesan U, et al. Hyperconnectivity is a fundamental response to neurological disruption. Neuropsychology 2015;29:59-75.

135. Hillary FG, Rajtmajer SM, Roman CA, et al. The rich get richer: Brain injury elicits hyperconnectivity in core subnetworks. PLoS One 2014;9:e104021.

136. Albert NB, Robertson EM, Miall RC. The resting human brain and motor learning. Curr Biol 2009;19:1023-7.

137. Guerra-Carrillo B, Mackey AP, Bunge SA. Resting-state fMRI a window into human brain plasticity. Neuroscientist 2014;20:522-33.

138. Johnen VM, Neubert F-X, Buch ER, et al. Causal manipulation of functional connectivity in a specific neural pathway during behaviour and at rest. eLife 2015;4:e04585.

139. Cannon WB. Organization for physiological homeostasis. Physiol Rev 1929;9:399-431.

140. Modell H, Cliff W, Michael J, et al. A physiologist's view of homeostasis. Adv Physiol Educ 2015;39:259-66.

141. Seeley TD. When is self-organization used in biological systems? Biol Bull 2002;202:314-8.

142. Prokopenko M. Guided self-organization. HFSP J 2009;3:287-9.

143. Yufik YM, Friston K. Life and understanding: the origins of "understanding" in self-organizing nervous systems. Front Syst Neurosci 2016;10:98.

144. Dijkstra EW. Self-stabilizing systems in spite of distributed control. Commun ACM 1974;17:643-4.

145. Schneider M. Self-stabilization. ACM Comput Surv 1993;25:45-67.

146. Johnson AP, Liu J, Millard AG, et al. Homeostatic fault tolerance in spiking neural networks: a dynamic hardware perspective. IEEE Trans Circuits Syst Regul Pap 2018;65:687-99.

147. Davis GW. Homeostatic control of neural activity: from phenomenology to molecular design. Annu Rev Neurosci 2006;29:307-23.

148. Faisal AA, Selen LPJ, Wolpert DM. Noise in the nervous system. Nat Rev Neurosci 2008;9:292-303.

149. Martin A, Barnes KA, Stevens WD. Spontaneous neural activity predicts individual differences in performance. Proc Natl Acad Sci U S A 2012;109:3201-2.

150. Abbott LF, Nelson SB. Synaptic plasticity: taming the beast. Nat Neurosci 2000;3(Suppl):1178-83.

151. Clapp WC, Hamm JP, Kirk IJ, et al. Translating LTP from animals to humans: a novel method for non-invasive assessment of cortical plasticity. Biol Psychiatry 2012;71:496-502.

152. Hebb DO. The organization of behavior: a neuropsychological theory. Hoboken, NJ: Wiley; 1949.

153. Turrigiano G. Homeostatic synaptic plasticity: local and global mechanisms for stabilizing neuronal function. Cold Spring Harb Perspect Biol 2012;4:a005736.

154. Turrigiano GG. The self-tuning neuron: synaptic scaling of excitatory synapses. Cell 2008;135:422-35.

155. Hsu D, Chen W, Hsu M, et al. An open hypothesis: Is epilepsy learned, and can it be unlearned? Epilepsy Behav EB 2008;13:511-22.

156. Pozo K, Goda Y. Unraveling mechanisms of homeostatic synaptic plasticity. Neuron 2010;66:337-51.

157. Vitureira N, Letellier M, Goda Y. Homeostatic synaptic plasticity: from single synapses to neural circuits. Curr Opin Neurobiol 2012;22:516-21.

158. Balduzzi D, Tononi G. What can neurons do for their brain? Communicate selectivity with bursts. Theory Biosci 2013;132:27-39.

159. Karabanov A, Siebner HR. Unravelling homeostatic interactions in inhibitory and excitatory networks in human motor cortex. J Physiol 2012;590:5557-8.

160. Yin J, Yuan Q. Structural homeostasis in the nervous system: a balancing act for wiring plasticity and stability. Front Cell Neurosci 2015;8:439.

161. Davis GW. Homeostatic signaling and the stabilization of neural function. Neuron 2013;80:718-28

162. Butz M, Wörgötter F, van Ooyen A. Activity-dependent structural plasticity. Brain Res Brain Res Rev 2009;60:287-305

163. Sjöström PJ, Rancz EA, Roth A, et al. Dendritic excitability and synaptic plasticity. Physiol Rev 2008;88:769-840.

164. Keck T, Keller GB, Jacobsen RI, et al. Synaptic scaling and homeostatic plasticity in the mouse visual cortex in vivo. Neuron 2013; 80:327-34.

165. Murthy VN, Schikorski T, Stevens CF, et al. Inactivity produces increases in neurotransmitter release and synapse size. Neuron 2001; 32:673-82.
166. Zuo Y, Yang G, Kwon E, et al. Long-term sensory deprivation prevents dendritic spine loss in primary somatosensory cortex. Nature 2005; $436: 261-5$

167. Deco G, Ponce-Alvarez A, Hagmann P, et al. How local excitationinhibition ratio impacts the whole brain dynamics. J Neurosci 2014; 34:7886-98.

168. Vogels TP, Sprekeler H, Zenke F, et al. Inhibitory plasticity balances excitation and inhibition in sensory pathways and memory networks. Science 2011;334:1569-73.

169. van Vreeswijk C, Sompolinsky H. Chaos in neuronal networks with balanced excitatory and inhibitory activity. Science 1996;274:1724-6.

170. Dierks T, Linden DE, Jandl M, et al. Activation of Heschl's gyrus during auditory hallucinations. Neuron 1999;22:615-21.

171. Hunter MD, Eickhoff SB, Miller TWR, et al. Neural activity in speech-sensitive auditory cortex during silence. Proc Natl Acad Sci U S A 2006;103:189-94.

172. Koch G, Ponzo V, Lorenzo FD, et al. Hebbian and anti-Hebbian spike-timing-dependent plasticity of human cortico-cortical connections. J Neurosci 2013;33:9725-33.

173. Ruan H, Saur T, Yao W-D. Dopamine-enabled anti-Hebbian timingdependent plasticity in prefrontal circuitry. Front Neural Circuits 2014;8:38.

174. Henson RNA, Rugg MD. Neural response suppression, haemodynamic repetition effects, and behavioural priming. Neuropsychologia 2003;41:263-70.

175. Barkus C, Sanderson DJ, Rawlins JNP, et al. What causes aberrant salience in schizophrenia? A role for impaired short-term habituation and the GRIA1 (GluA1) AMPA receptor subunit. Mol Psychiatry 2014;19:1060-70.

176. Holt DJ, Weiss AP, Rauch SL, et al. Sustained activation of the hippocampus in response to fearful faces in schizophrenia. Biol Psychiatry 2005;57:1011-9.

177. Rentzsch J, Shen C, Jockers-Scherübl MC, et al. Auditory mismatch negativity and repetition suppression deficits in schizophrenia explained by irregular computation of prediction error. PLoS One 2015;10:e0126775

178. Williams LE, Blackford JU, Luksik A, et al. Reduced habituation in patients with schizophrenia. Schizophr Res 2013;151:124-32.

179. Rubinov M, Knock SA, Stam CJ, et al. Small-world properties of nonlinear brain activity in schizophrenia. Hum Brain Mapp 2009; 30:403-16.

180. Northoff G. Is schizophrenia a spatiotemporal disorder of the brain's resting state? World Psychiatry 2015;14:34-5.

181. Northoff G, Duncan NW. How do abnormalities in the brain's spontaneous activity translate into symptoms in schizophrenia? From an overview of resting state activity findings to a proposed spatiotemporal psychopathology. Prog Neurobiol 2016;145146:26-45

182. Wolff A, Di Giovanni DA, Gómez-Pilar J, et al. The temporal signature of self: temporal measures of resting-state EEG predict selfconsciousness. Hum Brain Mapp 2019;40:789-803.

183. Butz M, Steenbuck ID, van Ooyen A. Homeostatic structural plasticity can account for topology changes following deafferentation and focal stroke. Front Neuroanat 2014;16:115.

184. Steenbuck ID, Butz M, Ruiter M, et al. Small-world topology is most efficient for homeostatic neuronal network repair. BMC Neurosci 2011;12:357.

185. Uranova NA. Structural changes in the neuropil of the frontal cortex in schizophrenia. Zh Nevropatol Psikhiatr Im S S Korsakova 1988; 88:52-8.

186. de Haan W, Mott K, van Straaten ECW, et al. Activity dependent degeneration explains hub vulnerability in Alzheimer's disease. PLoS Comput Biol 2012;8:e1002582.

187. van Winkel R, Stefanis NC, Myin-Germeys I. Psychosocial stress and psychosis: a review of the neurobiological mechanisms and the evidence for gene-stress interaction. Schizophr Bull 2008;34: 1095-105.

188. Weidenauer A, Bauer M, Sauerzopf U, et al. Making sense of: sensitization in schizophrenia. Int I Neuropsychopharmacol 2017;20:1-10.

189. Radley JJ, Rocher AB, Miller M, et al. Repeated stress induces dendritic spine loss in the rat medial prefrontal cortex. Cereb Cortex 2006; $16: 313-20$

190. Olive MF, Gass JT. Editorial: structural plasticity induced by drugs of abuse. Front Pharmacol 2015;6:88. 
191. Liston C, Gan W-B. Glucocorticoids are critical regulators of dendritic spine development and plasticity in vivo. Proc Natl Acad Sci U S A 2011;108:16074-9.

192. Jung CKE, Herms J. Structural dynamics of dendritic spines are influenced by an environmental enrichment: an in vivo imaging study. Cereb Cortex 2014;24:377-84.

193. Yagishita S, Hayashi-Takagi A, Ellis-Davies GCR, et al. A critical time window for dopamine actions on the structural plasticity of dendritic spines. Science 2014;345:1616-20.

194. Price R, Salavati B, Graff-Guerrero A, et al. Effects of antipsychotic D2 antagonists on long-term potentiation in animals and implications for human studies. Prog Neuropsychopharmacol Biol Psychiatry 2014;54:83-91.

195. Salavati B, Rajji TK, Price R, et al. Imaging-based neurochemistry in schizophrenia: a systematic review and implications for dysfunctional long-term potentiation. Schizophr Bull 2015;41:44-56.

196. Hadley JA, Kraguljac NV, White DM, et al. Change in brain network topology as a function of treatment response in schizophrenia: a longitudinal resting-state fMRI study using graph theory. NPJ Schizophr 2016;2:16014.

197. Dean CE. Antipsychotic-associated neuronal changes in the brain Toxic, therapeutic, or irrelevant to the long-term outcome of schizophrenia? Prog Neuropsychopharmacol Biol Psychiatry 2006;30:174-89.

198. Wang H-D, Deutch AY. Dopamine depletion of the prefrontal cortex induces dendritic spine loss: reversal by atypical antipsychotic drug treatment. Neuropsychopharmacology 2008;33:1276-86.

199. Lidow MS, Song Z-M, Castner SA, et al. Antipsychotic treatment induces alterations in dendrite- and spine-associated proteins in dopamine-rich areas of the primate cerebral cortex. Biol Psychiatry 2001:49:1-12

200. Critchlow HM, Maycox PR, Skepper JN, et al. Clozapine and haloperidol differentially regulate dendritic spine formation and synaptogenesis in rat hippocampal neurons. Mol Cell Neurosci 2006;32:356-65.

201. Bringas ME, Morales-Medina JC, Flores-Vivaldo Y, et al. Clozapine administration reverses behavioral, neuronal, and nitric oxide disturbances in the neonatal ventral hippocampus rat. Neuropharmacology 2012;62:1848-57.

202. Cho KKA, Khibnik L, Philpot BD, et al. The ratio of NR2A/B NMDA receptor subunits determines the qualities of ocular dominance plasticity in visual cortex. Proc Natl Acad Sci U S A 2009;106:5377-82.

203. Philpot BD, Cho KKA, Bear MF. Obligatory role of NR2A for metaplasticity in visual cortex. Neuron 2007;53:495-502.

204. Selemon LD, Zecevic N. Schizophrenia: a tale of two critical periods for prefrontal cortical development. Transl Psychiatry 2015;5:e623.

205. Huttenlocher PR, De Courten C, Garey LJ, et al. Synaptic development in human cerebral cortex. Int J Neurol 1982;16-17:144-54.

206. Petanjek Z, Judaš M, Šimic G, et al. Extraordinary neoteny of synaptic spines in the human prefrontal cortex. Proc Natl Acad Sci U S A 2011;108:13281-6.

207. Crow TJ, Ball J, Bloom SR, et al. Schizophrenia as an anomaly of development of cerebral asymmetry: a postmortem study and a proposal concerning the genetic basis of the disease. Arch Gen Psychiatry 1989:46:1145-50.

208. Harris JM, Moorhead TWJ, Miller P, et al. Increased prefrontal gyrification in a large high-risk cohort characterizes those who develop schizophrenia and reflects abnormal prefrontal development. Biol Psychiatry 2007;62:722-9.

209. Batalla A, Bargalló N, Gassó P, et al. Apoptotic markers in cultured fibroblasts correlate with brain metabolites and regional brain volume in antipsychotic-naive first-episode schizophrenia and healthy controls. Transl Psychiatry 2015;5:e626.

210. Massaad CA, Klann E. Reactive oxygen species in the regulation of synaptic plasticity and memory. Antioxid Redox Signal 2011;14: 2013-54.

211. Cannon M, Jones PB, Murray RM. Obstetric complications and schizophrenia: historical and meta-analytic review. Am J Psychiatry 2002;159:1080-92.

212. Haukvik UK, Schaer M, Nesvåg R, et al. Cortical folding in Broca's area relates to obstetric complications in schizophrenia patients and healthy controls. Psychol Med 2012;42:1329-37.

213. Brenowitz EA. Transsynaptic trophic effects of steroid hormones in an avian model of adult brain plasticity. Front Neuroendocrinol 2015;37:119-28.
214. Fester L, Rune GM. Sexual neurosteroids and synaptic plasticity in the hippocampus. Brain Res 2015;1621:162-9.

215. Reddy DS. Neurosteroids and their role in sex-specific epilepsies. Neurobiol Dis 2014;72 Pt B:198-209.

216. Bora E, Fornito A, Yücel M, et al. The effects of gender on grey matter abnormalities in major psychoses: a comparative voxelwise meta-analysis of schizophrenia and bipolar disorder. Psychol Med 2012;42:295-307.

217. Daskalakis ZJ, Christensen BK, Chen R, et al. Evidence for impaired cortical inhibition in schizophrenia using transcranial magnetic stimulation. Arch Gen Psychiatry 2002;59:347-54.

218. Hasan A, Nitsche MA, Herrmann M, et al. Impaired long-term depression in schizophrenia: a cathodal tDCS pilot study. Brain Stimulat 2012;5:475-83.

219. Rajji TK, Rogasch NC, Daskalakis ZJ, et al. Neuroplasticity-based brain stimulation interventions in the study and treatment of schizophrenia: a review. Can J Psychiatry 2013;58:93-8.

220. Rogasch NC, Daskalakis ZJ, Fitzgerald PB. Cortical inhibition, excitation, and connectivity in schizophrenia: a review of insights from transcranial magnetic stimulation. Schizophr Bull 2014;40:685-96.

221. Voineskos D, Rogasch NC, Rajii TK, et al. A review of evidence linking disrupted neural plasticity to schizophrenia. Can J Psychiatry 2013;58:86-92.

222. Fornito A, Zalesky A, Pantelis C, et al. Schizophrenia, neuroimaging and connectomics. NeuroImage 2012;62:2296-314.

223. Rubinov M, Bullmore E. Fledgling pathoconnectomics of psychiatric disorders. Trends Cogn Sci 2013;17:641-7.

224. Palaniyappan L, Liddle PF. Diagnostic discontinuity in psychosis: a combined study of cortical gyrification and functional connectivity. Schizophr Bull 2014;40:675-84.

225. Laskaris LE, Di Biase MA, Everall I, et al. Microglial activation and progressive brain changes in schizophrenia. $\mathrm{Br} J$ Pharmacol 2016;173:666-80

226. Paolicelli RC, Bolasco G, Pagani F, et al. Synaptic pruning by microglia is necessary for normal brain development. Science 2011;333:1456-8

227. Ripke S, Sanders AR, Kendler KS, et al. Genome-wide association study identifies five new schizophrenia loci. Nat Genet 2011; 43:969-76

228. Leza JC, García-Bueno B, Bioque M, et al. Inflammation in schizophrenia: a question of balance. Neurosci Biobehav Rev 2015;55:612-26.

229. Sekar A, Bialas AR, de Rivera H, et al. Schizophrenia risk from complex variation of complement component 4. Nature 2016; 530:177-83.

230. Mastellos DC. Complement emerges as a masterful regulator of CNS homeostasis, neural synaptic plasticity and cognitive function. Exp Neurol 2014:261:469-74.

231. Stephan AH, Barres BA, Stevens B. The complement system: an unexpected role in synaptic pruning during development and disease. Annu Rev Neurosci 2012;35:369-89.

232. Ramocki MB, Zoghbi HY. Failure of neuronal homeostasis results in common neuropsychiatric phenotypes. Nature 2008;455:912-8.

233. Hall J, Trent S, Thomas KL, et al. Genetic risk for schizophrenia: convergence on synaptic pathways involved in plasticity. Biol Psychiatry 2015;77:52-8.

234. Balu DT, Coyle JT. Neuroplasticity signaling pathways linked to the pathophysiology of schizophrenia. Neurosci Biobehav Rev 2011; 35:848-70.

235. Bakhshi K, Chance SA. The neuropathology of schizophrenia: a selective review of past studies and emerging themes in brain structure and cytoarchitecture. Neuroscience 2015;303:82-102.

236. Lewis DA, Curley AA, Glausier JR, et al. Cortical parvalbumin interneurons and cognitive dysfunction in schizophrenia. Trends Neurosci 2012;35:57-67.

237. Rotaru DC, Lewis DA, Gonzalez-Burgos G. The role of glutamatergic inputs onto parvalbumin-positive interneurons: relevance for schizophrenia. Rev Neurosci 2012;23:97-109.

238. Chen JL, Nedivi E. Highly specific structural plasticity of inhibitory circuits in the adult neocortex. Neuroscientist 2013;19:384-93.

239. Lau CG, Murthy VN. Activity-dependent regulation of inhibition via GAD67. J Neurosci 2012;32:8521-31.

240. Lazarus MS, Krishnan K, Huang ZJ. GAD67 deficiency in parvalbumin interneurons produces deficits in inhibitory transmission and network disinhibition in mouse prefrontal cortex. Cereb Cortex 1991;2015:1290-6. 
241. Donato F, Rompani SB, Caroni P. Parvalbumin-expressing basketcell network plasticity induced by experience regulates adult learning. Nature 2013;504:272-6.

242. Marsman A, van den Heuvel MP, Klomp DWJ, et al. Glutamate in schizophrenia: a focused review and meta-analysis of ${ }^{1} \mathrm{H}-\mathrm{MRS}$ studies. Schizophr Bull 2013;39:120-9.

243. Stone JM. Glutamatergic antipsychotic drugs: a new dawn in the treatment of schizophrenia? Ther Adv Psychopharmacol 2011;1:5-18

244. Plitman E, Nakajima S, de la Fuente-Sandoval C, et al. Glutamatemediated excitotoxicity in schizophrenia: a review. Eur Neuropsychopharmacol 2014;24:1591-605.

245. Hu W, MacDonald ML, Elswick DE, et al. The glutamate hypothesis of schizophrenia: evidence from human brain tissue studies. Ann N Y Acad Sci 2015;1338:38-57.

246. MacDonald ML, Ding Y, Newman J, et al. Altered glutamate protein co-expression network topology linked to spine loss in the auditory cortex of schizophrenia. Biol Psychiatry 2015;77:959-68

247. Merritt K, Egerton A, Kempton MJ, et al. Nature of glutamate alterations in schizophrenia: a meta-analysis of proton magnetic resonance spectroscopy studies. JAMA Psychiatry 2016;73:665-74.

248. Poels EMP, Kegeles LS, Kantrowitz JT, et al. Imaging glutamate in schizophrenia: review of findings and implications for drug discovery. Mol Psychiatry 2014;19:20-9.

249. Plitman E, Patel R, Chung JK, et al. Glutamatergic metabolites, volume and cortical thickness in antipsychotic-naïve patients with first-episode psychosis: implications for excitotoxicity. Neuropsychopharmacology 2016;41:2606-13.

250. Martino M, Magioncalda P, Yu H, et al. Abnormal resting-state connectivity in a substantia nigra-related striato-thalamo-cortical network in a large sample of first-episode drug-naïve patients with schizophrenia. Schizophr Bull 2018;44:419-31.

251. Yao W-D, Spealman RD, Zhang J. Dopaminergic signaling in dendritic spines. Biochem Pharmacol 2008;75:2055-69.

252. Corlett PR, Frith CD, Fletcher PC. From drugs to deprivation: a Bayesian framework for understanding models of psychosis. Psychopharmacology (Berl) 2009;206:515-30.

253. Fletcher PC, Frith CD. Perceiving is believing: a Bayesian approach to explaining the positive symptoms of schizophrenia. Nat Rev Neurosci 2009:10:48-58.

254. Howes OD, Kapur S. The dopamine hypothesis of schizophrenia: version III-the final common pathway. Schizophr Bull 2009;35:549-62.

255. Jardri R, Denève $S$. Circular inferences in schizophrenia. Brain 2013;136:3227-41.

256. Kapur S. Psychosis as a state of aberrant salience: a framework linking biology, phenomenology, and pharmacology in schizophrenia. Am J Psychiatry 2003;160:13-23.

257. Krishnan RR, Fivaz M, Kraus MS, et al. Hierarchical temporal processing deficit model of reality distortion and psychoses. Mol Psychiatry 2011;16:129-44

258. Whitford TJ, Ford JM, Mathalon DH, et al. Schizophrenia, myelination, and delayed corollary discharges: a hypothesis. Schizophr Bull 2012;38:486-94.

259. Stephan KE, Friston KJ, Frith CD. Dysconnection in schizophrenia: from abnormal synaptic plasticity to failures of self-monitoring. Schizophr Bull 2009;35:509-27.

260. Frohlich J, Van Horn JD. Reviewing the ketamine model for schizophrenia. J Psychopharmacol 2014;28:287-302.
261. Steeds H, Carhart-Harris RL, Stone JM. Drug models of schizophrenia. Ther Adv Psychopharmacol 2015;5:43-58.

262. Goto $Y$, Yang CR, Otani S. Functional and dysfunctional synaptic plasticity in prefrontal cortex: roles in psychiatric disorders. Biol Psychiatry 2010;67:199-207.

263. Keshavan MS, Mehta UM, Padmanabhan JL, et al. Dysplasticity, metaplasticity, and schizophrenia: implications for risk, illness, and novel interventions. Dev Psychopathol 2015;27:615-35.

264. Forsyth JK, Lewis DA. Mapping the consequences of impaired synaptic plasticity in schizophrenia through development: an integrative model for diverse clinical features. Trends Cogn Sci 2017; 21:760-78

265. Krystal JH, Anticevic A, Yang GJ, et al. Impaired tuning of neural ensembles and the pathophysiology of schizophrenia: a translational and computational neuroscience perspective. Biol Psychiatry 2017;81:874-85.

266. Cooper SJ. From Claude Bernard to Walter Cannon. Emergence of the concept of homeostasis. Appetite 2008;51:419-27.

267. Frese FJ, Knight EL, Saks E. Recovery from schizophrenia: with views of psychiatrists, psychologists, and others diagnosed with this disorder. Schizophr Bull 2009;35:370-80.

268. Harrow M, Hansford BG, Astrachan-Fletcher EB. Locus of control: relation to schizophrenia, to recovery, and to depression and psychosis-a 15-year longitudinal study. Psychiatry Res 2009;168: 186-92.

269. Damasio A, Damasio H. Exploring the concept of homeostasis and considering its implications for economics. J Econ Behav Organ 2016;126:125-9.

270. Jääskeläinen E, Juola P, Hirvonen N, et al. A systematic review and meta-analysis of recovery in schizophrenia. Schizophr Bull 2013;39: 1296-306.

271. Tandon R, DeQuardo JR, Taylor SF, et al. Phasic and enduring negative symptoms in schizophrenia: biological markers and relationship to outcome. Schizophr Res 2000;45:191-201.

272. Kirschner M, Aleman A, Kaiser S. Secondary negative symptoms-a review of mechanisms, assessment and treatment. Schizophr Res 2017;186:29-38.

273. Wondolowski J, Dickman D. Emerging links between homeostatic synaptic plasticity and neurological disease. Front Cell Neurosci 2013;7:223.

274. Davis J, Moylan S, Harvey BH, et al. Neuroprogression in schizophrenia: pathways underpinning clinical staging and therapeutic corollaries. Aust N Z J Psychiatry 2014;48:512-29.

275. Dunlop J, Brandon N. Schizophrenia drug discovery and development in an evolving era: are new drug targets fulfilling expectations? J Psychopharmacol 2015;29:230-8.

276. Fisher M, Loewy R, Hardy K, et al. Cognitive interventions targeting brain plasticity in the prodromal and early phases of schizophrenia. Annu Rev Clin Psychol 2013;9:435-63.

277. Hackos DH, Lupardus PJ, Grand T, et al. Positive allosteric modulators of GluN2A-containing NMDARs with distinct modes of action and impacts on circuit function. Neuron 2016;89:983-99.

278. Kauer JA, Malenka RC. Synaptic plasticity and addiction. Nat Rev Neurosci 2007;8:844-58.

279. Yang S, Weiner BD, Zhang LS, et al. Homeostatic plasticity drives tinnitus perception in an animal model. Proc Natl Acad Sci U S A 2011;108:14974-9. 